This is the pre-peer reviewed version of the following article:

de Roo, M., Veenstra, R., \& Kretschmer, T. (2022). Internalizing and externalizing correlates of parental overprotection as measured by the EMBU: A systematic review and meta-analysis. Social Development, 1-22.

which has been published in final form at https://doi.org/10.1111/sode.12590. This article may be used for non-commercial purposes in accordance with Wiley Terms and Conditions for Use of Self-Archived Versions.

\title{
Internalizing and Externalizing Correlates of Parental Overprotection as Measured by the EMBU: A Systematic Review and Meta-Analysis
}

\author{
Marthe de Roo, René Veenstra, and Tina Kretschmer \\ University of Groningen, the Netherlands
}

\begin{abstract}
Author Note
Potential conflict of interest: Seven of the screened studies (i.e., $2.8 \%$ of the total number of screened studies) were (co)authored by RV. Three of these studies were included in the present systematic review and meta-analysis, accounting for $10.3 \%$ of the total number of included studies. To avoid bias toward one's own articles as much as possible, RV was not involved in the screening process and in the risk-of-bias assessment. MdR and TK have no conflict of interests to disclose.
\end{abstract}

Correspondence concerning this article should be addressed to Marthe de Roo, Department of Pedagogy and Educational Sciences, Grote Rozenstraat 38, 9712TJ Groningen, the Netherlands. Email: marthe.de.roo@rug.nl 
Acknowledgements: Preparation of this manuscript has been supported by the European Research Council (ERC) Starting Grant awarded to Tina Kretschmer under the Horizon 2020 Research and Innovation program (Grant Agreement Number 757364, Title: Ghosts from the Past - Consequences of Adolescent Peer Relations Across Contexts and Generations). We also would like to thank Charlotte Vrijen for assisting with the meta-analysis. 


\begin{abstract}
Aspects of parenting including overprotection explain individual differences in child adjustment. This review and meta-analysis summarizes studies on parental overprotection and internalizing and externalizing problems. To ensure that findings could be compared as systematically as possible, the focus is on studies that used the overprotection scale of the Egna Minnen Beträffande Uppfostran ("Memories of my Parents' Upbringing”) (EMBU) questionnaire, a popular instrument to measure parental overprotection. In total, we extracted 176 effects from 29 studies. A modified version of the Newcastle-Ottawa Scale was used to perform quality assessments for the included studies. Parental overprotection was positively associated with offspring internalizing and externalizing problems, with overall estimates ranging from $r=.14$ to .18 . Moderator analyses suggested that effects of maternal were larger than effects of paternal overprotection. Other factors that moderated the strength of the association between overprotection and maladjustment included whether outcomes were selfreported or parent-reported, the design was cross-sectional or longitudinal, and publication year. Cultural context, age at exposure, and child sex did not explain differences between effect sizes. Most findings were based on cross-sectional studies and therefore do not constitute proof of causal relations. Many studies were of less-than-satisfactory quality regarding representativeness of the sample, descriptions of the data collection, and statistical analyses. There is a clear need for well-powered longitudinal studies to strengthen inferences about associations between parental overprotection and internalizing and externalizing problems.
\end{abstract}

Key words: parenting; overprotection; EMBU; psychopathology; meta-analysis; systematic review 


\section{Internalizing and Externalizing Correlates of Parental Overprotection as Measured by the EMBU: A Systematic Review and Meta-Analysis}

Parenting styles and behaviors including overprotection have received much attention as predictors of child and adolescent well-being and internalizing and externalizing outcomes (e.g., Pinquart, 2017), which, in turn, affect many aspects of adjustment, including peer acceptance, educational and job performance, and quality of life (Clayborne et al., 2019; Rapaport et al., 2005). The literature on the potential impact of overprotection on offspring development is substantial but is also difficult to survey given study heterogeneity in design, participants, and exposure and outcome measures, which hampers robust conclusions. To tackle this problem, we reviewed and meta-analyzed studies on parental overprotection and its association with offspring psychosocial adjustment.

Overprotective parents are excessively involved in children's daily activities and emotional experiences (Barber, 1996). The motivation is often benign and reflects parents' efforts to ensure children's safety and well-being. However, from a developmental perspective, parental overprotection can be harmful to adjustment. When children acquiesce to their parents' excessive worries, they can be at higher risk of developing internalizing symptoms, such as anxiety and depression. Conversely, children who resist their parents' overprotection might engage in externalizing behaviors, such as delinquency and substance use, as they explore opportunities for risk and responsibility on their own terms. Anxious or defiant behavior can, subsequently, elicit yet greater overprotection, which would then reinforce internalizing or externalizing symptoms (Hudson \& Rapee, 2001). What is more, overprotective parents hinder children's development of autonomy and independence and interfere with children's acquisition of skills and confidence by limiting the exposure to developmentally appropriate experiences (Schiffrin et al., 2014). In short, children with overprotective parents are likely at 
greater risk for maladjustment and possibly ill-prepared for the transition to adulthood (Ungar, 2009).

The literature on overprotection and adjustment is substantial but many studies are small and it is not clear how pervasive the effect is on long-term adjustment. Despite a general perception that overprotection is problematic, we do not know whether this conclusion holds universally or is specific to certain groups or contexts. To summarize and synthesize this body of work, our review and meta-analysis focuses on internalizing and externalizing correlates of parental overprotection as most studies included outcomes within these latent dimensions that organize common mental disorders. Whereas the internalizing spectrum incorporates a wide range of emotional symptoms that are directed inward, such as anxiety, the externalizing spectrum includes externally-focused behavioral symptoms, such as aggression.

Several instruments such as the Egna Minnen Beträffande Uppfostran ("Memories of my Parents' Upbringing”) (EMBU) and the Parental Bonding Instrument (PBI) assess parental overprotection but cannot necessarily be considered tests of the same underlying construct (Arrindell \& Engebretsen, 2000; Livianos-Aldana \& Rojo-Moreno, 1999). To ensure comparability of findings across studies, we only included studies that used the EMBU questionnaire to measure overprotection. The EMBU overprotection scale is considered a factorially purer measure of parental overprotection because the corresponding PBI measure has been shown to overlap strongly with the EMBU rejection scale (Arrindell et al., 1998; Arrindell \& Engebretsen, 2000). The absence of rejection components in the PBI reflects a lack of content validity. By exclusively reviewing work that used the EMBU, we focus on other sources of variation between studies rather than potentially having to ascribe heterogeneity to the measure as such.

The original 81-item EMBU questionnaire measures adult perceptions of their parent's rearing style (Perris et al., 1980). Redesigned versions enabled child (EMBU-C) and adolescent 
(EMBU-A) self-reports as well as parent-reports (EMBU-P) (Castro et al., 1993, 1997; Gerlsma et al., 1991). Finally, a shortened version of the EMBU-C (s-EMBU) is available (Arrindell et al., 1999). The different EMBU versions are valid and reliable instruments for assessing parenting practices (Arrindell et al., 2005; Castro et al., 1993; Markus et al., 2003). Results yielded from the different EMBU versions can be compared across studies (Aluja et al., 2006; Markus et al., 2003). Here, we focus on the EMBU overprotection scale (e.g., "Your parents want you to reveal their secrets to them"), which captures parenting behaviors indicative of fear and anxiety for the child's safety, guilt engendering, overinvolvement, and intrusiveness. Respondents rate their mother's and father's (EMBU-C, EMBU-A) or their own (EMBU-P) overprotective behavior on a four-point scale ranging from 1 (no, never) to 4 (yes, most of the time). The overprotection scale is part of all EMBU versions and we examined its associations with maladjustment.

Several moderators might influence such associations, including child and parent characteristics such as sex and age, study design such as whether self- or parent-reports were used to assess maladjustment, and whether contemporaneous associations were examined or whether overprotection was examined as developmentally preceding maladjustment. For instance, it is possible that overprotection affects boys and girls differently, which would not be surprising given that externalizing problems are more common in boys and internalizing problems in girls (e.g., Broidy et al., 2003). Similarly, effects of maternal and paternal overprotection may differ as mothers and fathers play distinct roles in the family that shape their parenting behavior (Yaffe, 2020). By testing for an influence of study design (i.e., crosssectional versus longitudinal), we address questions concerning the long-term significance of overprotection. Further, we included cultural context as a moderator to test whether overprotection elicits different responses in youth across cultures. Possibly, overprotection is not associated with maladjustment in collectivistic societies, in which authoritarian parenting 
including overprotection is more common (e.g., Rudy \& Grusec, 2006). Finally, we tested the moderating effect of publication year to determine if the influence of overprotection changed over time, although evidence for moderation by publication year may also indicate a so-called decline effect, according to which effect sizes decrease over time as methodological rigor increases and more confirmatory as opposed to exploratory studies are published (Schooler, 2011).

\section{Method}

This review adhered to the updated reporting guidelines provided by the Preferred Reporting Items for Systematic Reviews and Meta-Analyses (PRISMA; Page et al., 2021).

\section{Search Strategy}

Six electronic databases (ERIC, MEDLINE, PsycARTICLES, Psychology and Behavioral Sciences Collection, PsycINFO, SocINDEX) were searched with EBSCOhost during April 2020 using the following search terms: the string "EMBU" OR "Egna Minnen Beträffande Uppfostran" AND “overprotect*”. Supplementary material part one provides the full search strategies. To capture all the relevant studies, full-texts were searched instead of just titles or abstracts, and we restricted the search to peer-reviewed journal articles available in English. We did not restrict the search to a specific publication date range nor to any particular outcome at this point: Although the focus of this review is on internalizing and externalizing outcomes, Table S4 in the supplementary material provides information on studies examining other outcomes of overprotection.

\section{Study Inclusion and Exclusion Criteria}

Studies were included based on the following criteria:

(1) Empirical studies with cross-sectional, retrospective, or longitudinal design

(2) Studies examining direct associations between parental overprotection and child, adolescent, or adult internalizing and externalizing problems 
(3) Studies using the EMBU overprotection subscale to measure parental overprotection

(4) Studies focusing on population-based samples (i.e., non-selected groups of participants) Exclusion criteria:

(1) Studies using instruments other than the EMBU to measure overprotection

(2) Studies examining indirect associations between parental overprotection and internalizing and externalizing problems (without reported direct effects)

(3) Studies on outcomes other than internalizing or externalizing problems

(4) Studies focusing on high-risk samples or otherwise select groups of participants (e.g., clinical samples, ethnic or sexual minorities)

(5) Studies in languages other than English

(6) Meta-analyses and reviews, methodological papers (without empirical data), annotations, and commentaries

\section{Screening}

The PRISMA flowchart (Figure 1) depicts the selection procedure. After duplicate removal, titles and abstracts of 232 studies were independently screened by two raters (first and last author) in Rayyan (Ouzzani et al., 2016). Studies that did not meet the inclusion criteria were excluded $(n=116)$. Conflict cases were discussed and a consensus was reached. The full texts of the remaining 116 studies were scanned for eligibility by the first author; ambiguous cases were discussed with the last author. This resulted in exclusion of another 90 studies, mostly because instruments other than the EMBU were used or the EMBU overprotection subscale was not included in the analyses. Studies focusing on clinical samples as well as studies using the EMBU-scale with outcomes other than internalizing and externalizing problems that were excluded during this phase are listed in the supplementary material (Tables S4-6). Full texts for three articles could not be traced; consequently, these were not included. One additional study 
was identified through a general search. The screening procedure eventually resulted in 27 studies being included in this review.

The review was updated in September 2021. The search strategy remained the same; however, results were limited to studies published since April 2020. After removal of duplicates, titles and abstracts of sixteen studies were screened by one rater (first author) (Figure 1). During the initial screening, studies that did not meet the inclusion criteria were excluded $(n=5)$. Eleven full-text studies were assessed for eligibility, of which two were added to this review, resulting in a total of 29 studies.

\section{Assessment of Bias Risk}

The quality of selected studies was evaluated by the first author using a modified version of the Newcastle-Ottawa Scale adapted for cross-sectional studies (Wells et al., 2000, see supplementary material part 2). To ensure reliability, the last author assessed study quality for $\sim 50 \%$ of studies $(n=14)$. Inter-rater reliability was high $(85 \%)$ and disagreements were resolved by discussion. Studies were evaluated on representativeness of the sample, sample size, non-response, ascertainment of overprotection, assessment of internalizing and externalizing problems, and statistical procedure. A maximum of ten stars could be attributed and the average score was 4.59 (Table 1). Overall, the quality of the included studies was thus less than satisfactory.

\section{Effect Size Extraction}

Data was extracted by the first author for all relevant effect sizes, with the following priorities:

1) If effects were reported for boys and girls separately as well as for the complete sample, separate effects were extracted rather than the effect based on the full sample and 2) if effects of maternal and paternal overprotection were reported separately as well as the effect of total parental overprotection, separate effects were extracted. If information to compute effect sizes was unavailable or if only significant associations were reported, authors were emailed with a 
request to provide additional information and were given four weeks to respond. A reminder was sent after two weeks.

\section{Meta-Analytic Procedures and Analyses}

Pearson correlations $(r)$ were used as the main type of effect size. Standardized $\beta$ 's were converted to partial correlations using the formula $r=\beta+.05 \lambda$, where $\lambda$ equals 0 when $\beta$ is negative and $\lambda$ equals 1 when $\beta$ is non-negative (Peterson $\&$ Brown, 2005). Odds ratios were converted to correlations using an online effect size calculator (https://www.escal.site). When means and standard deviations were reported, we used the R package esc to convert these to correlations (Lüdecke, 2019). If effect sizes were unavailable because corresponding authors did not respond, we conservatively coded these effects as $r=0$. Effect sizes were converted to Fisher's $z$ scale prior to performing the analyses and results were converted back to correlations for presentation and interpretation.

Data were analyzed using multilevel random-effects models to account for dependency between effect sizes coming from the same samples and/or studies. Adjusted and unadjusted effects were analyzed in separate models. We also estimated separate models for the two outcome categories (i.e., internalizing and externalizing problems), resulting in four metaanalyses altogether. Mean effect sizes were interpreted following Cohen's (1988) conventions (i.e., $r=.10, .30$, and .50 indicate small, medium, and large effect sizes, respectively). We calculated $I^{2}$ separately for sampling variance (level 1), within-study variance (level 2), and between-study variance (level 3) and performed one-tailed log-likelihood-ratio tests to determine whether variance components were significantly larger than zero (Assink \& Wibbelink, 2016). Test statistics and confidence intervals for individual regression coefficients were based on the $t$-distribution (Knapp \& Hartung, 2003). To assess the likelihood of publication bias, we conducted Egger's test for funnel plot asymmetry using sample size as a moderator to account for dependence among effect sizes (Rodgers \& Pustejovsky, 2020). The 
significance level was set to the conventional level of .05. Meta-analyses were conducted in RStudio (version 1.4.1717) with R package metafor (version 3.0-2; Viechtbauer, 2010).

\section{Sensitivity Analyses}

We performed sensitivity analyses using only complete cases to determine the robustness of results across different types of models. That is, in the primary analyses, missing effect sizes were assumed to be null, potentially resulting in an underestimation of the true mean effect size. Complete case analysis presumably leads to a less conservative estimate of the actual effect but may also bias meta-analytic estimates because unreported effect sizes are more likely to be missing due to non-significance. Additional sensitivity analyses were performed in which influential outliers were excluded. To identify outliers, we computed standardized residuals and Cook's distances. Standardized residuals larger than 3.29 or smaller than -3.29 were considered outliers as well as Cook's distances larger than 4/n (Tabachnik \& Fidell, 2013).

\section{Moderator Analyses}

Moderator analyses were conducted to examine causes of heterogeneity. We only assessed moderators in models with significant within-study $\left(I^{2}\right.$ level 2) and/or between-study $\left(I^{2}\right.$ level 3) variability and when each category of the moderator contained at least three studies. Continuous moderators were mean-centered prior to analyses. Each moderator was first tested separately in a univariate model because including multiple moderators with multiple categories can inflate type II error rates (Hox et al., 2010). Significant moderators were then added to a multiple moderator model to examine the unique moderating effect of these variables. Only moderator effects found in multiple models were interpreted. Moderators tested here included publication year, child sex, maternal versus paternal overprotection, age at exposure, self-reported versus parent-reported outcome, cross-sectional versus longitudinal study design, and cultural context (individualistic vs. collectivistic). The latter was coded according to Hofstede's (2001) individualism index. It was not feasible to include EMBU-measure (i.e., EMBU-C, EMBU-P, 
or s-EMBU), specific outcome (e.g., anxiety, aggression), and outcome instrument as moderators because not all categories of these variables were based on at least three studies.

\section{Results}

Taken together, the 29 included studies produced 176 separate effects, of which 116 of overprotection on internalizing problems and 60 on externalizing problems. The studies, published between 1998 and 2021, were mostly cross-sectional (79.3\%) and reported on 26,925 participants, with sample sizes ranging from 89 to 2230 . Seven studies were based on the same sample (TRAILS) (Brinksma et al., 2021; Buschgens et al., 2010; Janssens et al., 2009; Oldehinkel et al., 2006; Sentse et al., 2009; van Oort et al., 2011; Veenstra et al., 2006). Age across studies ranged from 7 to 30 years, although most studies examined outcomes in childhood and adolescence.

Most samples were from European and North-American countries $(n=21)$, with remaining studies conducted in China $(n=3)$, Japan $(n=1)$, Russia $(n=1)$, Turkey $(n=1)$, Pakistan $(n=1)$, and Malaysia $(n=1)$. One study included only boys and another only girls but most studies used mixed-sex samples. Studies examined associations between overprotective parenting and broadband scales of internalizing problems, which include a wide range of emotional symptoms, or specific internalizing problems, such as anxiety and depression. Similarly, studies examined associations between overprotection and broadband scales of externalizing problems, including a range of behavioral problems, or specific externalizing problems, such as aggression or substance use.

With the exception of one study using parent-reports (EMBU-P), studies relied on childreport measures to assess overprotection (EMBU-C, EMBU-A, or s-EMBU). Fifteen studies used a single measure of parental overprotection (51.7\%) and thirteen studies (44.8\%) reported separate analyses for maternal and paternal overprotection. One study focused on only one parent. Outcomes were mostly self-reported (72.4\%) and else assessed by parents or teachers. 
Effect sizes included in the adjusted effects models were mainly corrected for demographic variables, such as sex and age. In four studies, estimates were corrected for baseline measures of maladjustment (Janssens et al., 2009; Muris et al., 2011; Sentse et al., 2009; Young et al., 2013). Six effect sizes (3.4\%) were missing and subsequently included as null effects $(r=0)$. Effects were missing either because studies reported only significant estimates $(n=5)$ or because information to compute effect sizes was unavailable $(n=1)$. One study was excluded from the analyses because trajectory models were used and as such, the categorical scaling on the outcome was not comparable to the continuous scaling used in the vast majority of studies (Brinksma et al., 2021). Another study was excluded in the adjusted effects model because a method was used that rendered the resulting effect sizes incomparable to effects of the other studies (Nishikawa et al., 2010). Finally, we refrained from including results from stepwise regression models in which overprotection was excluded from the final model because of non-significance (Roelofs et al., 2006; Xu, 2017).

\section{Primary Analyses and Sensitivity Analyses}

Parental overprotection as assessed by the EMBU was significantly positively associated with internalizing and externalizing problems (Table 2, Figures 2-5). Overall estimates ranged from $r=.14$ to .18 , indicating small to moderate effects (Cohen, 1988). Mean effects adjusted for covariates were similar to mean unadjusted effects. Results of sensitivity analyses were consistent with primary results. In line with expectations, overall estimates based on complete case analyses were somewhat larger than estimates from the primary analyses in which missing effect sizes were assumed to be null. Excluding influential outliers did not affect parameter estimates substantially. Results of the log-likelihood-ratio tests showed that there was significant within-study (level two) and between-study (level three) variance in all models except for the unadjusted effects model focusing on externalizing behavior, in which there was no significant within-study variability (Table S7). We did not find evidence for publication bias 
based on Egger's Test (Table S8). Qualitative results of studies focusing on clinical samples were similar to results of population-based studies, although studies based on clinical samples more often reported non-significant associations between overprotection and maladjustment (Tables S5-6).

\section{Moderator Analyses}

Heterogeneity indices revealed sufficient variance between effect sizes from the same study and between studies to proceed with moderator analyses in all meta-analytic models (Table S7). Results of univariate moderator analyses are presented in the supplementary material (Table S9). Here, we only interpret results of the multiple moderator models (see Table 3) including variables that were identified as significant moderators in the separate analyses. To facilitate interpretability, the reported mean moderator effects originate from univariate models.

\section{Unadjusted Effects Models}

Reporter of outcome was identified as a significant moderator in the unadjusted effects model on internalizing outcomes, with studies based on self-reported outcomes yielding larger associations between overprotection and internalizing problems than studies based on parentreported outcomes ( $r=.19$ for self-report and $r=.08$ for parent-report). In the model examining externalizing outcomes, we found a moderating effect of publication year. That is, the strength of the overall association between overprotection and externalizing problems was smaller in more recently published studies $(b=-.01)$. The strength of this effect, however, was negligible. Cultural context, age at EMBU measure, child sex, study design, and parent sex did not moderate either of the unadjusted models.

\section{Adjusted Effects Models}

Maternal versus paternal overprotection, study design, and reporter of outcome moderated the overall effect of overprotection on internalizing problems. More specifically, effects of maternal overprotection, $r=.23$, were larger than effects of paternal overprotection, $r=.17$ in 
the univariate model. Cross-sectional studies, $r=.21$, reported stronger overall associations than longitudinal studies, $r=.09$ in the univariate model. In addition, larger effects of overprotection on internalizing problems were found in studies based on self-reported outcomes, $r=.20$ versus parent-reported outcomes, $r=.07$ in the univariate model. For externalizing outcomes, maternal overprotection $(r=.20)$ also yielded larger effects than paternal overprotection $(r=.10)$. We did not find support for an influence of child sex, cultural context, age at EMBU measure, and publication year.

\section{Discussion}

We summarized and synthesized the literature on associations between parental overprotection as assessed by the EMBU and child, adolescent, and adult internalizing and externalizing outcomes. The EMBU is a widely-used instrument that has been translated into many languages and has been utilized in several studies on overprotection. This makes it a suitable choice to represent both breadth of the field while simultaneously allowing for comparisons that are not influenced by differences in instruments. Positive associations were found between overprotection and internalizing problems and overprotective parenting was also linked to externalizing and substance-related problems. All meta-analytic estimates were modest but robust across different types of models and methods. Missing data and outliers did not influence the results substantially. As such, overprotection indeed seems to be a parenting behavior associated with negative correlates.

We observed heterogeneity between effect sizes and examined whether methodological and substantive differences within and between studies function as moderators. Adjusted moderation models showed that cross-sectional studies where overprotection and internalizing problems were assessed simultaneously reported greater associations than longitudinal studies where overprotection is temporally preceding maladjustment. Adjusted effects usually came from studies that included sex and age in regression models but some also adjusted for baseline 
levels of maladjustment. Greater cross-sectional effect sizes are not surprising and might reflect 1) overestimated effects due to shared method variance when overprotection and adjustment are assessed at the same time and from the same reporter, 2) overprotection as parental reaction to maladjustment instead of the other way around, or, indeed 3) that the consequences of maladjustment are more severe closer in time and wane off after a while. Prospective longitudinal studies employing quasi-experimental designs such as matching on overprotection scores or cross-lagged designs that examine bidirectional prediction between overprotection and maladjustment are needed to fully understand the developmental ordering between both concepts. That said, the small associations observed here suggest that overprotection as assessed by the EMBU may be less problematic than it is sometimes theorized to be.

Next to that, our findings suggest that maternal and paternal overprotection affect offspring adjustment somewhat differently as effects of maternal overprotection were larger in adjusted effects models. Previous studies have also demonstrated that mothers are perceived as more controlling than fathers (Yaffe, 2020). Differences between mothers' and fathers' parenting behaviors may be rooted in traditional gender roles, with mothers still playing a more central role in child-rearing. On the contrary, we did not find that effects of overprotection differed between boys and girls, but the number of studies that reported separate effect sizes for boys and girls was low $(n=8)$. It would be of interest to examine in further research whether parental overprotection relates differently to maladjustment in boys and girls, considering the greater prevalence of internalizing problems among girls (Keiley et al., 2003), and greater prevalence of externalizing problems among boys (Broidy et al., 2003).

We did not find that effects of overprotection differed between countries with individualistic or collectivistic cultures, although studies have demonstrated that effective parenting behaviors vary cross-culturally (Jambunathan et al., 2000). For example, authoritarian parenting that is high in demandingness and low in responsiveness is not 
consistently linked to maladjustment in collectivistic cultures (Chao, 1994; Rudy \& Grusec, 2006). Perhaps, children and adolescents from more collectivistic cultures tend to interpret parental overprotection as an expression of love and care, whereas in more individualistic cultures such parenting is perceived as restrictive. However, because the number of studies from more collectivistic cultures was limited $(n=9)$, no robust conclusions can be drawn about differences. Systematic research on cross-cultural differences with regard to parenting and with respect to correlates of parenting should elucidate whether associations between overprotection and child maladjustment differ across cultural contexts.

\section{Quality of Studies}

The number of studies on links between overprotection as measured by the EMBU and maladjustment was large enough to warrant a review and meta-analysis and the positive overall associations appear to allow for robust conclusions. However, less-than-satisfactory quality ratings of most included studies imply at least three areas for improvement:

First, with respect to study design, participants were often recruited in universities or schools and most samples were small, which raises doubt as to whether results can be generalized. Additionally, only few studies reported response rates. Biased selection into the study and equally selective retention to follow-up also limit the generalizability of results. The widespread use of self-report outcome measures may have further biased results. Effect sizes based on self-reported outcomes were larger than effect sizes based on parent-reported outcomes in models focusing on internalizing problems, indicating the relevance of the reporter. Ideally, multiple-informant data are used to reduce shared method variance.

Second, failure to adjust for genetic effects could lead to an overestimation of the parenting effect. Children's inherited genes may evoke overprotective behavior in parents, or, instead, parental overprotection may be explained by the same (inherited) genes that explain offspring maladjustment. Only four studies included a measure of parental psychopathology as 
a proxy for genetic risk to correct for the possibility that observed associations were due to genetic confounding (Buschgens et al., 2010; Oldehinkel et al., 2006; Sentse et al., 2009; Veenstra et al., 2006). Future studies on parenting and social development could benefit considerably from integrating genetic information on both parents and children (for example, using polygenic scores) to detect potential confounding and consequently better understand parenting influence (Harden, 2021).

Third, cross-sectional designs are overrepresented but cannot determine causality and not even temporal order of constructs as is possible in longitudinal designs that adjust for baseline levels of the outcome. Longitudinal assessments thus allow for stronger conclusions about whether overprotection is linked to increases in psychological and behavioral problems or if, as would be plausible as well, maladjustment is associated with overprotective rearing (Siqueland et al., 1996). Without empirical data elucidating the direction of effects, conclusions regarding temporal order of overprotection and outcomes are hampered.

\section{Limitations of the Review}

Some limitations with respect to this review should also be noted. First, although we reduced heterogeneity by focusing on a single operationalization of overprotection, effects were based on a wide range of conceptualizations of outcomes and outcome instruments and, thus, the results of our meta-analyses do not reflect homogeneous effects. However, if an overall effect is found, as in our review, this adds to the robustness of the finding that parental overprotection as assessed by the EMBU is associated with offspring maladjustment. Further, in light of the current discussions on publication bias, it is important to note that significant results are more easily published than null findings, which threatens the validity of systematic reviews and metaanalyses. A number of well-carried-out but non-significant studies may not have been published and were therefore not included in this review. 
Next, the analyses presented here were based on population samples. Clinical samples and specifically selected populations were excluded. Parenting, especially overprotection, might be evoked in response to the needs of a child, and these might be different for high-risk samples. As such, overprotection in special populations might not carry the same risk as it does for children and adolescents without clinical diagnoses or for otherwise at-risk populations. A focus on population-based research therefore increases the likelihood that the results apply to a wider variety of individuals.

Finally, seven studies were based on the TRAILS sample. TRAILS findings were consistent with other studies, but the repeated use of the same data could lead to a biased literature in which the number of studies in favor of a particular phenomenon or association is overestimated. Meta-analyses can account for such bias either by selecting one study per sample or by applying multilevel methods, as also done here, and it is crucial to keep this in mind in narrative reviews as well.

\section{Conclusion}

Higher levels of parental overprotection as assessed by the EMBU are linked to offspring maladjustment, with somewhat larger effects for maternal overprotection. Smaller associations were reported in longitudinal studies, which suggests that the negative impact of overprotective parenting as measured with the EMBU might not persist over time. We did not find that effects of overprotection differed between countries with individualistic and collectivistic cultures; however, the number of studies from collectivistic cultures was limited. Rigorous cross-cultural work is needed to examine cultural factors in outcomes of overprotection. Finally, suboptimal quality and cross-sectional design of many studies are important limitations that need to be tackled in future studies, as estimates might be biased, and conclusions pertaining to temporal order and long-term developmental impact of overprotection on maladjustment are hampered. 
In sum, although our findings suggest that overprotection is linked to maladjustment, there are avenues to substantially improve the quality and, consequently, the value of this research field. 


\section{References}

*Affrunti, N. W., \& Ginsburg, G. S. (2012). Maternal overcontrol and child anxiety: The mediating role of perceived competence. Child Psychiatry \& Human Development, 43(1), 102-112. https://doi.org/10.1007/s10578-011-0248-z

Aluja, A., Barrio, V. D. and García, L. F. (2006). Do parents and adolescents differ in their perceptions of rearing styles? Analysis of the EMBU versions for parents and adolescents. Scandinavian Journal of Psychology, 47, 103-

108. https://doi.org/10.1111/j.1467-9450.2006.00497.x

Arrindell, W. A., Gerlsma, C., Vandereycken, W., Hageman, W. J. J. M., \& Daeseleire, T. (1998). Convergent validity of the dimensions underlying the parental bonding instrument (PBI) and the EMBU. Personality and Individual Differences, 24(3), 341350. https://doi.org/10.1016/S0191-8869(97)00187-6

Arrindell, W. A., Sanavio, E., Aguilar, G., Sica, C., Hatzichristou, C., Eisemann, M., Recinos, L. A., Gaszner, P., Peter, M., Battagliese, G., Kállai, J., \& van der Ende, J. (1999). The development of a short form of the EMBU: Its appraisal with students in Greece, Guatemala, Hungary and Italy. Personality and Individual Differences, 27(4), 613628. https://doi.org/10.1016/S0191-8869(98)00192-5

Arrindell, W. A., \& Engebretsen, A. A. (2000). Convergent validity of the short-EMBU and the Parental Bonding Instrument (PBI): Dutch findings. Clinical Psychology \& Psychotherapy, 7(4), 262-266. https://doi.org/10.1002/10990879(200010)7:4<262::AID-CPP257>3.0.CO;2-9

Arrindell, W., Akkerman, A., Bages, N., Feldman, L., Caballo, V., Oei, T. P., Torres, B., Canalda, G., Castro, J., Montgomery, I., Davis, M., Calvo, M., Kenardy, J., Palenzuela, D., Richards, J., Leong, C. C., Simón, M., \& Zaldívar, F. (2005). The Short-EMBU in Australia, Spain, and Venezuela: Factorial invariance, and 
associations with sex roles, self-esteem, and Eysenckian personality dimensions. European Journal of Psychological Assessment, 21, 56-66. https://doi.org/10.1027/1015-5759.21.1.56

Assink, M., \& Wibbelink, C. J. M. (2016). Fitting three-level meta-analytic models in R: A step-by-step tutorial. The Quantitative Methods for Psychology, 12(3), 154-174. https://doi.org/10.20982/tqmp.12.3.p154

Barber, B. K. (1996). Parental psychological control: Revisiting a neglected construct. Child Development, 67(6), 3296-3319. https://doi.org/10.2307/1131780

*Berkien, M., Louwerse, A., Verhulst, F., \& van der Ende, J. (2012). Children's perceptions of dissimilarity in parenting styles are associated with internalizing and externalizing behavior. European Child \& Adolescent Psychiatry, 21(2), 79-85. https://doi.org/10.1007/s00787-011-0234-9

Broidy, L. M., Nagin, D. S., Tremblay, R. E., Bates, J. E., Brame, B., Dodge, K. A., Fergusson, D., Horwood, J. L., Loeber, R., Laird, R., Lynam, D. R., Moffitt, T. E., Pettit, G. S., \& Vitaro, F. (2003). Developmental trajectories of childhood disruptive behaviors and adolescent delinquency: A six-site, cross-national study. Developmental Psychology, 39(2), 222-245. https://doi.org/10.1037//0012-1649.39.2.222

*Brinksma, D. M., Hoekstra, P. J., de Bildt, A., Buitelaar, J. K., van den Hoofdakker, B. J., Hartman, C. A., \& Dietrich, A. (2021). Parental rejection in early adolescence predicts a persistent ADHD symptom trajectory across adolescence. European Child \& Adolescent Psychiatry. Advance online publication. https://doi.org/10.1007/s00787021-01844-0

*Buschgens, C. J. M., van Aken, M. A. G., Swinkels, S. H. N., Ormel, J., Verhulst, F. C., \& Buitelaar, J. K. (2010). Externalizing behaviors in preadolescents: Familial risk to externalizing behaviors and perceived parenting styles. European Child \& Adolescent 
Psychiatry, 19(7), 567-575. https://doi.org/10.1007/s00787-009-0086-8

Castro, J., Toro, J., van der Ende, J., \& Arrindell, W. A. (1993). Exploring the feasibility of assessing perceived parental rearing styles in Spanish children with the EMBU. The International Journal of Social Psychiatry, 39(1), 47-57.

https://doi.org/10.1177/002076409303900105

Chao, R. K. (1994). Beyond parental control and authoritarian parenting style:

Understanding Chinese parenting through the cultural notion of training. Child Development, 65(4), 1111-1119. https://doi.org/10.1111/j.1467-8624.1994.tb00806.x

Clayborne, Z. M., Varin, M., \& Colman, I. (2019). Systematic review and meta-analysis:

Adolescent depression and long-term psychosocial outcomes. Journal of the American Academy of Child \& Adolescent Psychiatry, 58(1), 72-79.

https://doi.org/10.1016/j.jaac.2018.07.896

Cohen, J. (1988). Statistical Power Analysis for the Behavioral Sciences (2nd ed.). Routledge. https://doi.org/10.4324/9780203771587

Gerlsma, C., Arrindell, W. A., van der Veen, N., \& Emmelkamp, P. M. G. (1991). A parental rearing style questionnaire for use with adolescents: Psychometric evaluation of the EMBU-A. Personality and Individual Differences, 12(12), 1245-1253. https://doi.org/10.1016/0191-8869(91)90196-I

*Haciomeroglu, B., \& Karanci, A. N. (2014). Perceived parental rearing behaviours, responsibility attitudes and life events as predictors of obsessive compulsive symptomatology: Test of a cognitive model. Behavioural and Cognitive Psychotherapy, 42(6), 641-652. https://doi.org/10.1017/S1352465813000581

Harden, K. P. (2021). 'Reports of my death were greatly exaggerated': Behavior genetics in the postgenomic era. Annual Review of Psychology, 72, 37-60. https://doi.org/10.1146/annurev-psych-052220-103822 
Hofstede, G. (2001). Culture's Consequences: Comparing Values, Behaviors, Institutions and Organizations Across Nations (2nd ed). SAGE.

Hox, J., Moerbeek, M., \& van de Schoot, R. (2010). Multilevel Analysis: Techniques and Applications, Second Edition (2nd ed.). Routledge. https://doi.org/10.4324/9780203852279

Hudson, J. L., \& Rapee, R. M. (2001). Parent-child interactions and anxiety disorders: An observational study. Behaviour Research and Therapy, 39(12), 1411-1427. https://doi.org/10.1016/S0005-7967(00)00107-8

*Irons, C., Gilbert, P., Baldwin, M. W., Baccus, J. R., \& Palmer, M. (2006). Parental recall, attachment relating and self-attacking/self-reassurance: Their relationship with depression. British Journal of Clinical Psychology, 45(3), 297-308. https://doi.org/10.1348/014466505X68230

Jambunathan, S., Burts, D. C., \& Pierce, S. (2000). Comparisons of parenting attitudes among five ethnic groups in the United States. Journal of Comparative Family Studies, 31(4), 395-406. https://doi.org/10.3138/jcfs.31.4.395

*Janssens, K. A. M., Oldehinkel, A. J., \& Rosmalen, J. G. M. (2009). Parental overprotection predicts the development of functional somatic symptoms in young adolescents. The Journal of Pediatrics, 154(6), 918-923. https://doi.org/10.1016/j.jpeds.2008.12.023

Keiley, M. K., Lofthouse, N., Bates, J. E., Dodge, K. A., \& Pettit, G. S. (2003). Differential risks of covarying and pure components in mother and teacher reports of externalizing and internalizing behavior across ages 5 to 14. Journal of Abnormal Child Psychology, 31(3), 267-283. https://doi.org/10.1023/a:1023277413027

Knapp, G., \& Hartung, J. (2003). Improved tests for a random effects meta-regression with a single covariate. Statistics in Medicine, 22(17), 2693-2710. https://doi.org/10.1002/sim.1482 
*Knappe, S., Lieb, R., Beesdo, K., Fehm, L., Ping Low, N. C., Gloster, A. T., \& Wittchen, H. (2009). The role of parental psychopathology and family environment for social phobia in the first three decades of life. Depression and Anxiety, 26(4), 363-370. https://doi.org/10.1002/da.20527

*Liu, Y., Xiao, Y., Ran, H., He, X., Jiang, L., Wang, T., Yang, R. X., Xu, X., Yang, G., \& Lu, J. (2020). Association between parenting and non-suicidal self-injury among adolescents in Yunnan, China: A cross-sectional survey. PeerJ, 8, e10493. https://doi.org/10.7717/peerj.10493

Livianos-Aldana, L., \& Rojo-Moreno, L. (1999). On the convergent validity of two parental rearing behaviour scales: EMBU and PBI. Acta Psychiatrica Scandinavica, 100(4), 263-269. https://doi.org/10.1111/j.1600-0447.1999.tb10860.x

Lüdecke, D. (2019). esc: Effect size computation for meta-analysis (version 0.5.1). https://cran.r-project.org/package=esc

Markus, M. T., Lindhout, I. E., Boer, F., Hoogendijk, T. H. G., \& Arrindell, W. A. (2003). Factors of perceived parental rearing styles: The EMBU-C examined in a sample of Dutch primary school children. Personality and Individual Differences, 34(3), 503519. https://doi.org/10.1016/S0191-8869(02)00090-9

*Mousavi, S. E., Low, W. Y., \& Hashim, A. H. (2016). Perceived parenting styles and cultural influences in adolescent's anxiety: A cross-cultural comparison. Journal of Child and Family Studies, 25(7), 2102-2110. https://doi.org/10.1007/s10826-0160393-x

*Mukhtar, S., \& Mahmood, Z. (2018). Moderating role of perceived social support between perceived parenting styles and relational aggression in adolescents. Journal of Aggression, Maltreatment \& Trauma, 27(8), 831-845.

https://doi.org/10.1080/10926771.2018.1468842 
*Muris, P., Meesters, C., \& Berg, S. V. D. (2003a). Internalizing and externalizing problems as correlates of self-reported attachment style and perceived parental rearing in normal adolescents. Journal of Child \& Family Studies, 12(2), 171-183.

https://doi.org/10.1023/A:1022858715598

*Muris, P., Meesters, C., \& van Brakel, A. (2003b). Assessment of anxious rearing behaviors with a modified version of "Egna Minnen Beträffande Uppfostran" questionnaire for children. Journal of Psychopathology and Behavioral Assessment, 25(4), 229-237. https://doi.org/10.1023/A:1025894928131

*Muris, P., van Brakel, A. M. L., Arntz, A., \& Schouten, E. (2011). Behavioral inhibition as a risk factor for the development of childhood anxiety disorders: A longitudinal study. Journal of Child and Family Studies, 20(2), 157-170. https://doi.org/10.1007/s10826$010-9365-8$

*Niditch, L. A., \& Varela, R. E. (2012). Perceptions of parenting, emotional self-efficacy, and anxiety in youth: Test of a mediational model. Child \& Youth Care Forum, 41(1), 2135. https://doi.org/10.1007/s10566-011-9150-x

*Nishikawa, S., Sundbom, E., \& Hägglöf, B. (2010). Influence of perceived parental rearing on adolescent self-concept and internalizing and externalizing problems in Japan. Journal of Child and Family Studies, 19(1), 57-66. https://doi.org/10.1007/s10826009-9281-y

*Oldehinkel, A. J., Veenstra, R., Ormel, J., de Winter, A. F., \& Verhulst, F. C. (2006). Temperament, parenting, and depressive symptoms in a population sample of preadolescents. Journal of Child Psychology and Psychiatry, 47(7), 684-695. https://doi.org/10.1111/j.1469-7610.2005.01535.x

Ouzzani, M., Hammady, H., Fedorowicz, Z., \& Elmagarmid, A. (2016). Rayyan-A web and mobile app for systematic reviews. Systematic Reviews, 5(1), 210. 
https://doi.org/10.1186/s13643-016-0384-4

Page, M. J., McKenzie, J. E., Bossuyt, P. M., Boutron, I., Hoffmann, T. C., Mulrow, C. D., Shamseer, L., Tetzlaff, J. M., Akl, E. A., Brennan, S. E., Chou, R., Glanville, J., Grimshaw, J. M., Hróbjartsson, A., Lalu, M. M., Li, T., Loder, E. W., Mayo-Wilson, E., McDonald, S., ... Moher, D. (2021). The PRISMA 2020 statement: An updated guideline for reporting systematic reviews. $B M J, 372, \mathrm{n} 71$. https://doi.org/10.1136/bmj.n71

Perris, C., Jacobsson, L., Lindström, H., von Knorring, L., \& Perris, H. (1980). Development of a new inventory assessing memories of parental rearing behaviour. Acta Psychiatrica Scandinavica, 61(4), 265-274. https://doi.org/10.1111/j.16000447.1980.tb00581.x

Peterson, R. A., \& Brown, S. P. (2005). On the use of beta coefficients in meta-analysis. Journal of Applied Psychology, 90(1), 175-181. https://doi.org/10.1037/00219010.90 .1 .175

Pinquart, M. (2017). Associations of parenting dimensions and styles with externalizing problems of children and adolescents: An updated meta-analysis. Developmental Psychology, 53(5), 873-932. https://doi.org/10.1037/dev0000295

Rapaport, M. H., Clary, C., Fayyad, R., \& Endicott, J. (2005). Quality-of-life impairment in depressive and anxiety disorders. The American Journal of Psychiatry, 162(6), 11711178. https://doi.org/10.1176/appi.ajp.162.6.1171

Rodgers, M. A., \& Pustejovsky, J. E. (2020). Evaluating meta-analytic methods to detect selective reporting in the presence of dependent effect sizes. Psychological Methods. https://doi.org/10.1037/met0000300

*Roelofs, J., Meesters, C., ter Huurne, M., Bamelis, L., \& Muris, P. (2006). On the links between attachment style, parental rearing behaviors, and internalizing and 
externalizing problems in non-clinical children. Journal of Child and Family Studies, 15(3), 319-332. https://doi.org/10.1007/s10826-006-9025-1

*Ruchkin, V. V., Eisemann, M., \& Hägglöf, B. (1998). Aggression in delinquent adolescents versus controls: The role of parental rearing. Children \& Society, 12(4), 275-282. https://doi.org/10.1111/j.1099-0860.1998.tb00081.x

Rudy, D., \& Grusec, J. (2006). Authoritarian parenting in individualist and collectivist groups: Associations with maternal emotion and cognition and children's self-esteem. Journal of Family Psychology, 20, 68-78. https://doi.org/10.1037/0893-3200.20.1.68

Schiffrin, H. H., Liss, M., Miles-McLean, H., Geary, K. A., Erchull, M. J., \& Tashner, T. (2014). Helping or hovering? The effects of helicopter parenting on college students' well-being. Journal of Child and Family Studies, 23(3), 548-557. https://doi.org/10.1007/s10826-013-9716-3

Schooler, J. (2011). Unpublished results hide the decline effect. Nature, 470(7335), 437. https://doi.org/10.1038/470437a

*Sentse, M., Veenstra, R., Lindenberg, S., Verhulst, F. C., \& Ormel, J. (2009). Buffers and risks in temperament and family for early adolescent psychopathology: Generic, conditional, or domain-specific effects? The TRAILS study. Developmental Psychology, 45(2), 419-430. https://doi.org/10.1037/a0014072

Siqueland, L., Kendall, P. C., \& Steinberg, L. (1996). Anxiety in children: Perceived family environments and observed family interaction. Journal of Clinical Child Psychology, 25(2), 225-237. https://doi.org/10.1207/s15374424jccp2502_12

*Smári, J., Martinsson, D. R., \& Einarsson, H. (2010). Rearing practices and impulsivity/hyperactivity symptoms in relation to inflated responsibility and obsessive-compulsive symptoms. Scandinavian Journal of Psychology, 51(5). 392397. https://doi.org/10.1111/j.1467-9450.2010.00819.x 
*Stevens, E. N., Bardeen, J. R., \& Murdock, K. W. (2015). Parenting behaviors and anxiety in young adults: Effortful control as a protective factor. Journal of Individual Differences, 36(3), 170-176. https://doi.org/10.1027/1614-0001/a000169

Tabachnik, B. G., \& Fidell, L. S. (2013). Using Multivariate Statistics (6th ed.). Pearson. Ungar, M. (2009). Overprotective parenting: Helping parents provide children the right amount of risk and responsibility. The American Journal of Family Therapy, 37(3), 258-271. https://doi.org/10.1080/01926180802534247

*van Brakel, A. M. L., Muris, P., Bögels, S. M., \& Thomassen, C. (2006). A multifactorial model for the etiology of anxiety in non-clinical adolescents: Main and interactive effects of behavioral inhibition, attachment and parental rearing. Journal of Child and Family Studies, 15(5), 568-578. https://doi.org/10.1007/s10826-006-9061-x

*van Oort, F. V. A., Greaves-Lord, K., Ormel, J., Verhulst, F. C., \& Huizink, A. C. (2011). Risk indicators of anxiety throughout adolescence: The TRAILS study. Depression and Anxiety, 28(6), 485-494. https://doi.org/10.1002/da.20818

*Veenstra, R., Lindenberg, S., Oldehinkel, A. J., De Winter, A. F., \& Ormel, J. (2006). Temperament, environment, and antisocial behavior in a population sample of preadolescent boys and girls. International Journal of Behavioral Development, 30(5), 422-432. https://doi.org/10.1177/0165025406071490

Viechtbauer, W. (2010). Conducting meta-analyses in R with the metafor package. Journal of Statistical Software, 36(3), 1-48. https://doi.org/10.18637/jss.v036.i03

*Villegas-Pantoja, M., Guzmán-Facundo, F., Alonso-Castillo, M., de la Rubia, J. M., \& López-García, K. (2018). Parenting behaviors and their relationship with alcohol involvement in Mexican teenagers and young adults. Journal of Child \& Adolescent Substance Abuse, 27(4), 227-237. https://doi.org/10.1080/1067828X.2018.1455612 Wells, G. A., Shea, B., O’Connell, D., Peterson, J. E. A., Welch, V., Losos, M., \& Tugwell, P. 
(2000). The Newcastle-Ottawa Scale (NOS) for assessing the quality of nonrandomized studies in meta-analyses.

http://www.ohri.ca/programs/clinical_epidemiology/nosgen.pdf. Accessed 26 January 2021.

*Xia, G., \& Qian, M. (2001). The relationship of parenting style to self-reported mental health among two subcultures of Chinese. Journal of Adolescence, 24(2), 251-260. https://doi.org/10.1006/jado.2001.0375

*Xu, J., Ni, S., Ran, M., \& Zhang, C. (2017). The relationship between parenting styles and adolescents' social anxiety in migrant families: A study in Guangdong, China. Frontiers in Psychology, 8, 626. https://doi.org/10.3389/fpsyg.2017.00626

Yaffe, Y. (2020). Systematic review of the differences between mothers and fathers in parenting styles and practices. Current Psychology. Advance online publication. https://doi.org/10.1007/s12144-020-01014-6

*Young, B. J., Wallace, D. P., Imig, M., Borgerding, L., Brown-Jacobsen, A. M., \& Whiteside, S. P. H. (2013). Parenting behaviors and childhood anxiety: A psychometric investigation of the EMBU-C. Journal of Child and Family Studies, 22(8), 1138-1146. https://doi.org/10.1007/s10826-012-9677-y 
Table 1

Study Characteristics and Quality Assessment ( $\mathrm{n}=29)$

\begin{tabular}{|c|c|c|c|c|c|c|c|c|c|}
\hline Study & $\begin{array}{c}\text { Sample } \\
\text { size and } \\
\% \text { male at } \\
\text { baseline }\end{array}$ & $\begin{array}{c}n \\
\text { Effect } \\
\text { Sizes }\end{array}$ & Setting & Sample & $\begin{array}{c}\text { Age range or } M_{\text {age at }} \\
\text { time of exposure and } \\
\text { outcome }\end{array}$ & $\begin{array}{l}\text { Study } \\
\text { design }\end{array}$ & $\begin{array}{l}\text { EMBU } \\
\text { measure }\end{array}$ & $\begin{array}{l}\text { Outcome and } \\
\text { assessment of } \\
\text { outcome }\end{array}$ & Quality assessment \\
\hline $\begin{array}{l}\text { Affrunti \& } \\
\text { Ginsburg (2012) }\end{array}$ & $\begin{array}{c}89 \\
(51.7 \%)\end{array}$ & 6 & US & $\begin{array}{l}\text { Community- } \\
\text { based }\end{array}$ & 9.58 & $\mathrm{CS}$ & $\mathrm{C}$ & $\begin{array}{l}\text { Anxiety: self- } \\
\text { report (SCARED) }\end{array}$ & 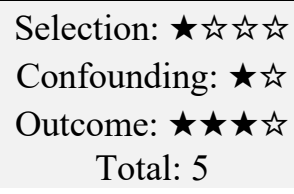 \\
\hline $\begin{array}{l}\text { Berkien et al. } \\
\text { (2012) }\end{array}$ & $\begin{array}{c}658 \\
(46.0 \%)\end{array}$ & 8 & Netherlands & $\begin{array}{l}\text { Population- } \\
\text { based }\end{array}$ & $\begin{array}{l}\text { Girls: } 13.7 \\
\text { Boys: } 13.4\end{array}$ & CS & $\mathrm{C}$ & $\begin{array}{l}\text { Internalizing and } \\
\text { externalizing } \\
\text { behavior: self- } \\
\text { report (YSR) }\end{array}$ & $\begin{array}{l}\text { Selection: } \star \star \text { 论访 } \\
\text { Confounding: } \star \text { 论 } \\
\text { Outcome: } \star \star \text { 论访 } \\
\text { Total: } 5\end{array}$ \\
\hline $\begin{array}{l}\text { Brinksma et al. } \\
(2021)\end{array}$ & $\begin{array}{c}1730 \\
(51.0 \%)\end{array}$ & 3 & Netherlands & $\begin{array}{l}\text { Population- } \\
\text { based }\end{array}$ & $\begin{array}{l}\text { Exposure: } 10.0-12.6 \\
\text { Outcome: } 10.0-18.4\end{array}$ & $\mathrm{~L}$ & $\mathrm{C}$ & $\begin{array}{l}\text { ADHD symptoms: } \\
\text { parent-report } \\
\text { (CBCL) }\end{array}$ & 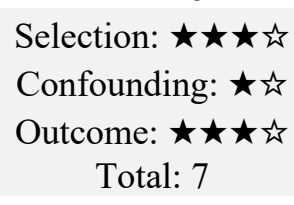 \\
\hline $\begin{array}{l}\text { Buschgens et al. } \\
(2010)\end{array}$ & $\begin{array}{c}2230 \\
(49.2 \%)\end{array}$ & 14 & Netherlands & $\begin{array}{l}\text { Population- } \\
\text { based }\end{array}$ & 11.09 & CS & $\mathrm{C}$ & $\begin{array}{l}\text { Externalizing } \\
\text { behavior: parent- } \\
\text { report (CBCL) and } \\
\text { teacher-report } \\
\text { (TCP) }\end{array}$ & $\begin{array}{c}\text { Selection: } \star \star \text { 弥访 } \\
\text { Confounding: } \star \text { 论 } \\
\text { Outcome: } \star \star \star \star \\
\text { Total: } 7\end{array}$ \\
\hline $\begin{array}{l}\text { Haciomeroglu \& } \\
\text { Karanci (2014) }\end{array}$ & $\begin{array}{c}300 \\
(51.0 \%)\end{array}$ & 2 & Turkey & $\begin{array}{l}\text { University } \\
\text { students }\end{array}$ & 19.55 & CS & $\mathrm{S}$ & $\begin{array}{l}\text { OCD symptoms: } \\
\text { self-report (PI- } \\
\text { WSUR) }\end{array}$ & 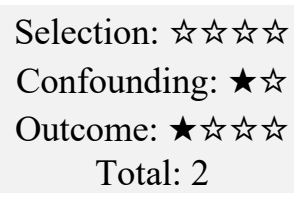 \\
\hline $\begin{array}{l}\text { Irons et al. } \\
\text { (2006) }\end{array}$ & $\begin{array}{c}197 \\
(13.2 \%)\end{array}$ & 2 & $\begin{array}{l}\text { UK and } \\
\text { Canada }\end{array}$ & $\begin{array}{l}\text { University } \\
\text { students }\end{array}$ & Unknown & CS & $\mathrm{S}$ & $\begin{array}{c}\text { Depressive } \\
\text { symptomatology: } \\
\text { self-report (CES- } \\
\text { D) }\end{array}$ & 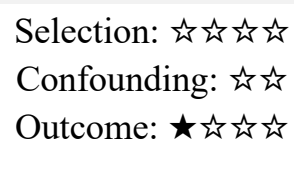 \\
\hline
\end{tabular}




\begin{tabular}{|c|c|c|c|c|c|c|c|c|c|}
\hline $\begin{array}{l}\text { Janssens et al. } \\
\text { (2009) }\end{array}$ & $\begin{array}{c}2230 \\
(49.2 \%)\end{array}$ & 6 & Netherlands & $\begin{array}{l}\text { Population- } \\
\text { based }\end{array}$ & $\begin{array}{l}\text { Exposure: } 11.09 \\
\text { Outcome: } 13.56\end{array}$ & $\mathrm{~L}$ & $\mathrm{C}$ & $\begin{array}{l}\text { Functional somatic } \\
\text { problems: self- } \\
\text { report (YSR) }\end{array}$ & $\begin{array}{l}\text { Selection: } \star \star \star \star \\
\text { Confounding: } \star \star \star \\
\text { Outcome: } \star \star \star \hbar \hbar \\
\text { Total: } 7\end{array}$ \\
\hline $\begin{array}{l}\text { Knappe et al. } \\
(2009)\end{array}$ & $\begin{array}{c}1395 \\
(51.2 \%)\end{array}$ & 2 & Germany & $\begin{array}{l}\text { Population- } \\
\text { based }\end{array}$ & $14-24$ & CS & FEE $^{\mathrm{a}}$ & $\begin{array}{c}\text { Social phobia: } \\
\text { computer-assisted } \\
\text { interview (M- } \\
\text { CIDI) }\end{array}$ & $\begin{array}{c}\text { Selection: } \star \star \star \hbar \hbar \\
\text { Confounding: } \star \star \hbar \\
\text { Outcome: } \star \star \star \star \star \star \\
\text { Total: } 7\end{array}$ \\
\hline Liu et al. (2020) & $\begin{array}{c}2705 \\
(46.0 \%)\end{array}$ & 12 & China & $\begin{array}{l}\text { Population- } \\
\text { based }\end{array}$ & 13.42 & CS & $\mathrm{S}$ & $\begin{array}{l}\text { Non-suicidal self- } \\
\text { injury: self-report } \\
\text { (NSSI Function } \\
\text { Assessment Scale) }\end{array}$ & 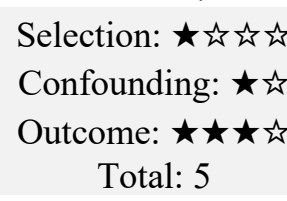 \\
\hline $\begin{array}{l}\text { Mousavi et al. } \\
\text { (2016) }\end{array}$ & $\begin{array}{c}227 \\
(53.7 \%)\end{array}$ & 16 & Malaysia & $\begin{array}{l}\text { Students from } \\
\text { private and } \\
\text { international } \\
\text { secondary } \\
\text { schools }\end{array}$ & 15.12 & CS & $\mathrm{C}$ & $\begin{array}{l}\text { Anxiety: self- } \\
\text { report (SCAS) }\end{array}$ & 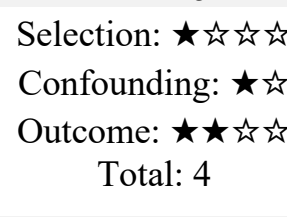 \\
\hline $\begin{array}{l}\text { Mukhtar \& } \\
\text { Mahmood (2018) }\end{array}$ & $\begin{array}{c}200 \\
(50 \%)\end{array}$ & 2 & Pakistan & $\begin{array}{l}\text { Students from } \\
\text { public and } \\
\text { private schools } \\
\text { and colleges }\end{array}$ & 15.69 & CS & $\mathrm{C}$ & $\begin{array}{c}\text { Relational } \\
\text { aggression: self- } \\
\text { report (DARAS) }\end{array}$ & 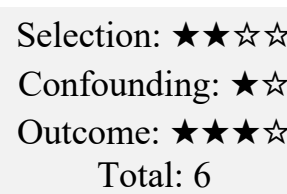 \\
\hline $\begin{array}{l}\text { Muris et al. } \\
\text { (2003a) }\end{array}$ & $\begin{array}{c}742 \\
(53.5 \%)\end{array}$ & 12 & Netherlands & $\begin{array}{c}\text { Secondary } \\
\text { school students }\end{array}$ & 14.45 & CS & $\mathrm{C}$ & $\begin{array}{l}\text { Internalizing and } \\
\text { externalizing } \\
\text { problems: self- } \\
\text { report (YSR) }\end{array}$ & 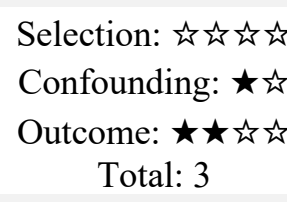 \\
\hline $\begin{array}{l}\text { Muris et al. } \\
\text { (2003b) }\end{array}$ & $\begin{array}{c}1196 \\
(51.8 \%)\end{array}$ & 4 & Netherlands & $\begin{array}{c}\text { Primary and } \\
\text { secondary } \\
\text { school students }\end{array}$ & 12.60 & CS & $\mathrm{C}$ & $\begin{array}{l}\text { Anxiety: self- } \\
\text { report (SCAS, } \\
\text { SCARED, PSWQ) }\end{array}$ & 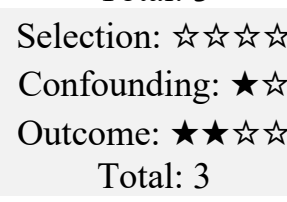 \\
\hline $\begin{array}{l}\text { Muris et al. } \\
\text { (2011) }\end{array}$ & $\begin{array}{c}261 \\
(44.1 \%)\end{array}$ & 12 & Netherlands & $\begin{array}{l}\text { Primary school } \\
\text { students }\end{array}$ & $\begin{array}{c}\text { Exposure 1: } 7.1 \\
\text { Exposure } 2: 8.1 \\
\text { Outcome: } 10.1\end{array}$ & $\mathrm{~L}$ & $\mathrm{P}$ & $\begin{array}{l}\text { Anxiety: parent- } \\
\text { report (SCARED) }\end{array}$ & 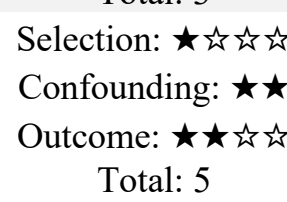 \\
\hline
\end{tabular}




\begin{tabular}{|c|c|c|c|c|c|c|c|c|c|}
\hline $\begin{array}{l}\text { Niditch \& Varela } \\
\text { (2012) }\end{array}$ & $\begin{array}{c}124 \\
(37 \%)\end{array}$ & 4 & US & $\begin{array}{l}\text { Middle and } \\
\text { high school } \\
\text { students }\end{array}$ & 14.82 & CS & $\mathrm{C}$ & $\begin{array}{l}\text { Anxiety: self- } \\
\text { report (RCMAS) }\end{array}$ & 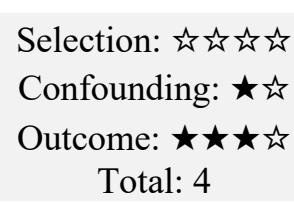 \\
\hline $\begin{array}{l}\text { Nishikawa et al. } \\
\text { (2010) }\end{array}$ & $\begin{array}{c}193 \\
(74.1 \%)\end{array}$ & 8 & Japan & $\begin{array}{l}\text { High school } \\
\text { students }\end{array}$ & 16.4 & CS & $\mathrm{C}$ & $\begin{array}{l}\text { Internalizing and } \\
\text { externalizing } \\
\text { problems: self- } \\
\text { report (YSR) }\end{array}$ & 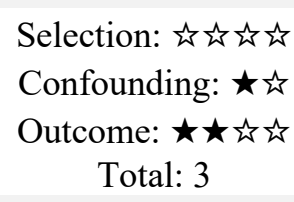 \\
\hline $\begin{array}{l}\text { Oldehinkel et al. } \\
\text { (2006) }\end{array}$ & $\begin{array}{c}2230 \\
(49.2 \%)\end{array}$ & 3 & Netherlands & $\begin{array}{l}\text { Population- } \\
\text { based }\end{array}$ & 11.09 & CS & $\mathrm{C}$ & $\begin{array}{l}\text { Depression: self- } \\
\text { report (YSR) and } \\
\text { parent-report } \\
(\mathrm{CBCL})\end{array}$ & $\begin{array}{l}\text { Selection: } \star \star \succsim \downarrow \\
\text { Confounding: } \star \star \downarrow \\
\text { Outcome: } \star \star \star \star \star \\
\text { Total: } 7\end{array}$ \\
\hline $\begin{array}{l}\text { Roelofs et al. } \\
(2006)\end{array}$ & $\begin{array}{c}237 \\
(48.1 \%)\end{array}$ & 12 & Netherlands & $\begin{array}{l}\text { Primary school } \\
\text { students }\end{array}$ & 10.5 & $\mathrm{CS}$ & $\mathrm{C}$ & $\begin{array}{l}\text { Internalizing } \\
\text { symptoms: self- } \\
\text { report (RCADS); } \\
\text { Externalizing } \\
\text { symptoms: self- } \\
\text { report (TRA) }\end{array}$ & 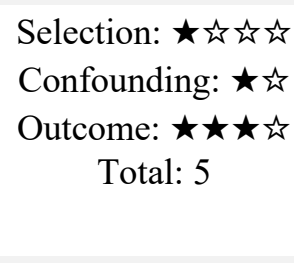 \\
\hline $\begin{array}{l}\text { Ruchkin et al. } \\
\text { (1998) }\end{array}$ & $\begin{array}{c}108 \\
(100 \%)\end{array}$ & 8 & Russia & $\begin{array}{c}\text { Secondary } \\
\text { school students }\end{array}$ & 15.0 & CS & $\mathrm{C}$ & $\begin{array}{l}\text { Aggression: self- } \\
\text { report (AQ) }\end{array}$ & 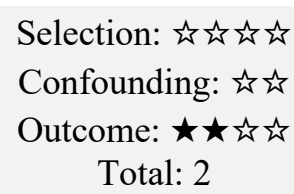 \\
\hline $\begin{array}{l}\text { Sentse et al. } \\
(2009)\end{array}$ & $\begin{array}{c}2149 \\
(49.2 \%)\end{array}$ & 6 & Netherlands & $\begin{array}{l}\text { Population- } \\
\text { based }\end{array}$ & $\begin{array}{l}\text { Exposure: } 11.09 \\
\text { Outcome: } 13.55\end{array}$ & $\mathrm{~L}$ & $\mathrm{C}$ & $\begin{array}{l}\text { Internalizing and } \\
\text { externalizing } \\
\text { problems: self- } \\
\text { report (YSR) and } \\
\text { parent-report } \\
\text { (CBCL) }\end{array}$ & $\begin{array}{c}\text { Selection: } \star \star \star \star \\
\text { Confounding: } \star \star \\
\text { Outcome: } \star \star \star \star \\
\text { Total: } 9\end{array}$ \\
\hline $\begin{array}{l}\text { Smári et al. } \\
\text { (2010) }\end{array}$ & $\begin{array}{c}570 \\
(41.6 \%)\end{array}$ & 2 & Iceland & $\begin{array}{c}\text { Secondary } \\
\text { school students }\end{array}$ & $\begin{array}{c}18-20: 77.4 \% \\
21-24: 4.6 \% \\
>30: 3.5 \%\end{array}$ & CS & $\mathrm{S}$ & $\begin{array}{l}\text { OCD symptoms: } \\
\text { self-report (OCI- } \\
\text { R) }\end{array}$ & 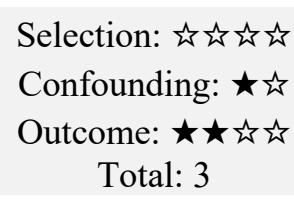 \\
\hline $\begin{array}{l}\text { Stevens et al. } \\
\text { (2015) }\end{array}$ & $\begin{array}{c}162 \\
(48 \%)\end{array}$ & 2 & US & $\begin{array}{l}\text { University } \\
\text { students }\end{array}$ & 19.7 & CS & $\mathrm{C}$ & $\begin{array}{l}\text { Anxiety: self- } \\
\text { report (BAI) }\end{array}$ & 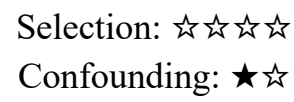 \\
\hline
\end{tabular}




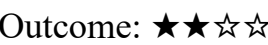

Total: 3

\begin{tabular}{|c|c|c|c|c|c|c|c|c|c|}
\hline $\begin{array}{l}\text { van Brakel et al. } \\
(2006)\end{array}$ & $\begin{array}{c}644 \\
(52.3 \%)\end{array}$ & 2 & Netherlands & $\begin{array}{c}\text { Secondary } \\
\text { school students }\end{array}$ & 12.7 & $\mathrm{CS}$ & $\mathrm{C}$ & $\begin{array}{l}\text { Anxiety: self- } \\
\text { report (SCARED) }\end{array}$ & 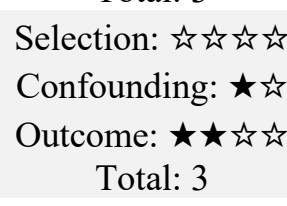 \\
\hline $\begin{array}{l}\text { van Oort et al. } \\
\text { (2011) }\end{array}$ & $\begin{array}{l}2220 \\
(49 \%)\end{array}$ & 1 & Netherlands & $\begin{array}{l}\text { Population- } \\
\text { based }\end{array}$ & $\begin{array}{c}\text { Exposure: } 10-12 \\
\text { Outcome 1: } 12-15 \\
\text { Outcome } 2: 14-18\end{array}$ & $\mathrm{~L}$ & $\mathrm{C}$ & $\begin{array}{l}\text { Anxiety: self- } \\
\text { report (RCADS) }\end{array}$ & 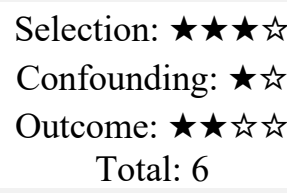 \\
\hline $\begin{array}{l}\text { Veenstra et al. } \\
(2006)\end{array}$ & $\begin{array}{c}2230 \\
(49.2 \%)\end{array}$ & 3 & Netherlands & $\begin{array}{c}\text { Population- } \\
\text { based }\end{array}$ & 11.09 & $\mathrm{CS}$ & $\mathrm{C}$ & $\begin{array}{l}\text { Antisocial } \\
\text { behavior: self- } \\
\text { report (YSR) and } \\
\text { parent-report } \\
(\mathrm{CBCL})\end{array}$ & $\begin{array}{c}\text { Selection: } \star \star \star \hbar \\
\text { Confounding: } \star \star \\
\text { Outcome: } \star \star \star \star \\
\text { Total: } 7\end{array}$ \\
\hline $\begin{array}{l}\text { Villegas-Pantoja } \\
\text { et al. (2018) }\end{array}$ & $\begin{array}{c}276 \\
(58.0 \%)\end{array}$ & 6 & Mexico & $\begin{array}{c}\text { Students } \\
\text { enrolled in } \\
\text { urban technical } \\
\text { schools }\end{array}$ & $15-24$ & $\mathrm{CS}$ & $\mathrm{C}$ & $\begin{array}{l}\text { Alcohol use: self- } \\
\text { report (AUDIT) }\end{array}$ & 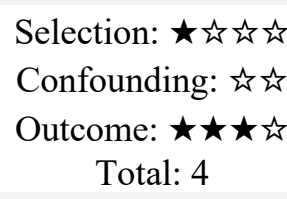 \\
\hline $\begin{array}{l}\text { Xia \& Qian } \\
(2001)\end{array}$ & $\begin{array}{c}127 \\
(74.8 \%)\end{array}$ & 12 & China & $\begin{array}{l}\text { High school } \\
\text { students }\end{array}$ & $16-22$ & CS & $\mathrm{C}$ & $\begin{array}{l}\text { Mental health } \\
\text { symptoms: self- } \\
\text { report (SCL-90) }\end{array}$ & 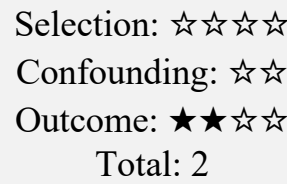 \\
\hline Xu et al. (2017) & $\begin{array}{c}1345 \\
(59.3 \%)\end{array}$ & 3 & China & $\begin{array}{l}\text { Middle school } \\
\text { students }\end{array}$ & 13.70 & CS & $\mathrm{S}$ & $\begin{array}{l}\text { Social anxiety: } \\
\text { self-report (SCS- } \\
\text { R) }\end{array}$ & 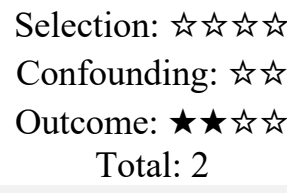 \\
\hline $\begin{array}{l}\text { Young et al. } \\
\text { (2013) }\end{array}$ & $\begin{array}{c}150 \\
(50.7 \%)\end{array}$ & 3 & US & $\begin{array}{c}\text { Community- } \\
\text { based }\end{array}$ & 10.5 & $\mathrm{~L}$ & $\mathrm{C}$ & $\begin{array}{l}\text { Anxiety: parent- } \\
\text { report (SCAS) }\end{array}$ & $\begin{array}{l}\text { Selection: } \star \star \\
\text { Confounding: } \star \star \star \\
\text { Outcome: } \star \star \star \\
\text { Total: } 6\end{array}$ \\
\hline
\end{tabular}

Note. $\mathrm{CL}=$ cross-sectional, $\mathrm{L}=$ longitudinal, $\mathrm{C}=$ EMBU-C (child-report), $\mathrm{P}=$ EMBU-P (parent-report), $\mathrm{S}=\mathrm{s}-\mathrm{EMBU}$ (short version of the EMBU-C).

${ }^{\text {a }}$ German version of the EMBU-C. 
Table 2

Unadjusted and Adjusted Effect Sizes for Parental Overprotection and Internalizing and Externalizing Problems

\begin{tabular}{|c|c|c|c|c|c|c|c|c|c|c|c|c|c|c|}
\hline \multirow{2}{*}{\multicolumn{2}{|c|}{ Model }} & \multicolumn{5}{|c|}{ Primary Analyses } & \multicolumn{8}{|c|}{ Sensitivity Analyses } \\
\hline & & \multicolumn{2}{|c|}{ Descriptive Statistics } & \multicolumn{3}{|c|}{ (Partial) Correlation } & \multicolumn{4}{|c|}{ Complete Case Analyses } & \multicolumn{4}{|c|}{ Analyses Without Influential Outliers } \\
\hline $\begin{array}{l}\text { Adjusted } \\
\text { or Unadj }\end{array}$ & Outcome & $\begin{array}{c}n \text { Samples/ } \\
\text { Publications }\end{array}$ & $\begin{array}{c}n \text { Effects/ } \\
\text { Participants }^{\mathrm{a}}\end{array}$ & $r$ & $95 \% \mathrm{CI}$ & $p$ & $\begin{array}{l}n \text { Excl. } \\
\text { Effects }\end{array}$ & $r$ & $95 \% \mathrm{CI}$ & $p$ & $\begin{array}{l}n \text { Excl. } \\
\text { Outliers }\end{array}$ & $r$ & $95 \% \mathrm{CI}$ & $p$ \\
\hline \multirow{2}{*}{ Unadjusted } & Internalizing & $16 / 17$ & $58 / 11,021$ & .18 & {$[.13, .22]$} & $<.001$ & - & - & - & - & 1 & .17 & {$[.13, .21]$} & $<.001$ \\
\hline & Externalizing & $6 / 9$ & $29 / 3745$ & .15 & {$[.11, .18]$} & $<.001$ & - & - & - & - & 1 & .14 & {$[.11, .17]$} & $<.001$ \\
\hline \multirow{2}{*}{ Adjusted } & Internalizing & $18 / 21$ & $58 / 13,077$ & .18 & {$[.14, .23]$} & $<.001$ & 4 & .19 & {$[.15, .24]$} & $<.001$ & - & - & - & - \\
\hline & Externalizing & $6 / 8$ & $31 / 4375$ & .14 & {$[.07, .20]$} & $<.001$ & 2 & .16 & {$[.09, .22]$} & $<.001$ & 1 & .12 & {$[.05, .20]$} & $<.001$ \\
\hline
\end{tabular}

Note. Unadj. = unadjusted, Excl. = excluded. —, not applicable.

${ }^{a}$ Participant numbers were counted only once per sample. 


\section{Table 3}

Results of Multiple Moderator Analyses

\begin{tabular}{|c|c|c|c|c|c|c|c|c|c|}
\hline \multicolumn{2}{|c|}{ Model } & \multicolumn{8}{|c|}{ Moderator Analyses } \\
\hline $\begin{array}{l}\text { Adjusted } \\
\text { or Unadj. }\end{array}$ & Outcome & Moderator & $\begin{array}{c}n \text { Effects/ } \\
\text { Publications }\end{array}$ & $b$ & $95 \% \mathrm{CI}$ & $F(\mathrm{dfs})^{\mathrm{a}}$ & $p$ & $I_{\text {level } 2}{ }^{\mathrm{b}}$ & $I_{\text {level } 3}{ }^{\mathrm{c}}$ \\
\hline \multirow[t]{2}{*}{ Unadj. } & Internalizing & Self- vs. parent-reported (ref) outcome & $54 / 15$ & 0.12 & {$[0.12,0.23]$} & $4.40(1,52)$ & .04 & $.002 *$ & $.005^{*}$ \\
\hline & Externalizing & Publication year (continuous) & $29 / 9$ & -0.01 & {$[-0.01,0.00]$} & $4.91(1,27)$ & .04 & .00 & $.001 *$ \\
\hline \multirow[t]{7}{*}{ Adjusted } & Internalizing & & $40 / 10$ & - & - & $12.69(5,34)$ & $<.001$ & $.002 *$ & .001 \\
\hline & & Maternal (ref) vs. paternal overprotection & - & -0.07 & {$[-0.11,-0.02]$} & - & .004 & - & - \\
\hline & & Cross-sectional (ref) vs. longitudinal design & - & -0.16 & {$[-0.24,-0.08]$} & - & $<.001$ & - & - \\
\hline & & Self- vs. parent-reported (ref) outcome & - & 0.16 & {$[0.03,0.29]$} & - & .02 & - & - \\
\hline & & Publication year (continuous) & - & -0.01 & {$[-0.02,0.02]$} & - & .11 & - & - \\
\hline & & Individualistic (ref) vs. collectivistic culture & - & -0.08 & {$[-0.23,0.07]$} & - & .27 & - & - \\
\hline & Externalizing & Maternal (ref) vs. paternal overprotection & $22 / 5$ & -0.10 & {$[-0.16,-0.03]$} & $9.33(1,20)$ & .006 & $.002 *$ & $.01 *$ \\
\hline
\end{tabular}

Note. Unadj. = unadjusted, ref = reference category. - , not applicable.

${ }^{a}$ Omnibus test of all regression coefficients in the model based on $F$ distribution.

${ }^{\mathrm{b}}$ Within-Study Variance (Level 2). Significant values indicate the presence of other, unexplored moderators.

${ }^{c}$ Between-Study Variance (Level 3). Significant values indicate the presence of other, unexplored moderators.

$* p<.05$. 


\section{Figure 1}

PRISMA Flow Diagram Showing the Process of Study Selection for Inclusion in the Systematic Review and Meta-Analysis

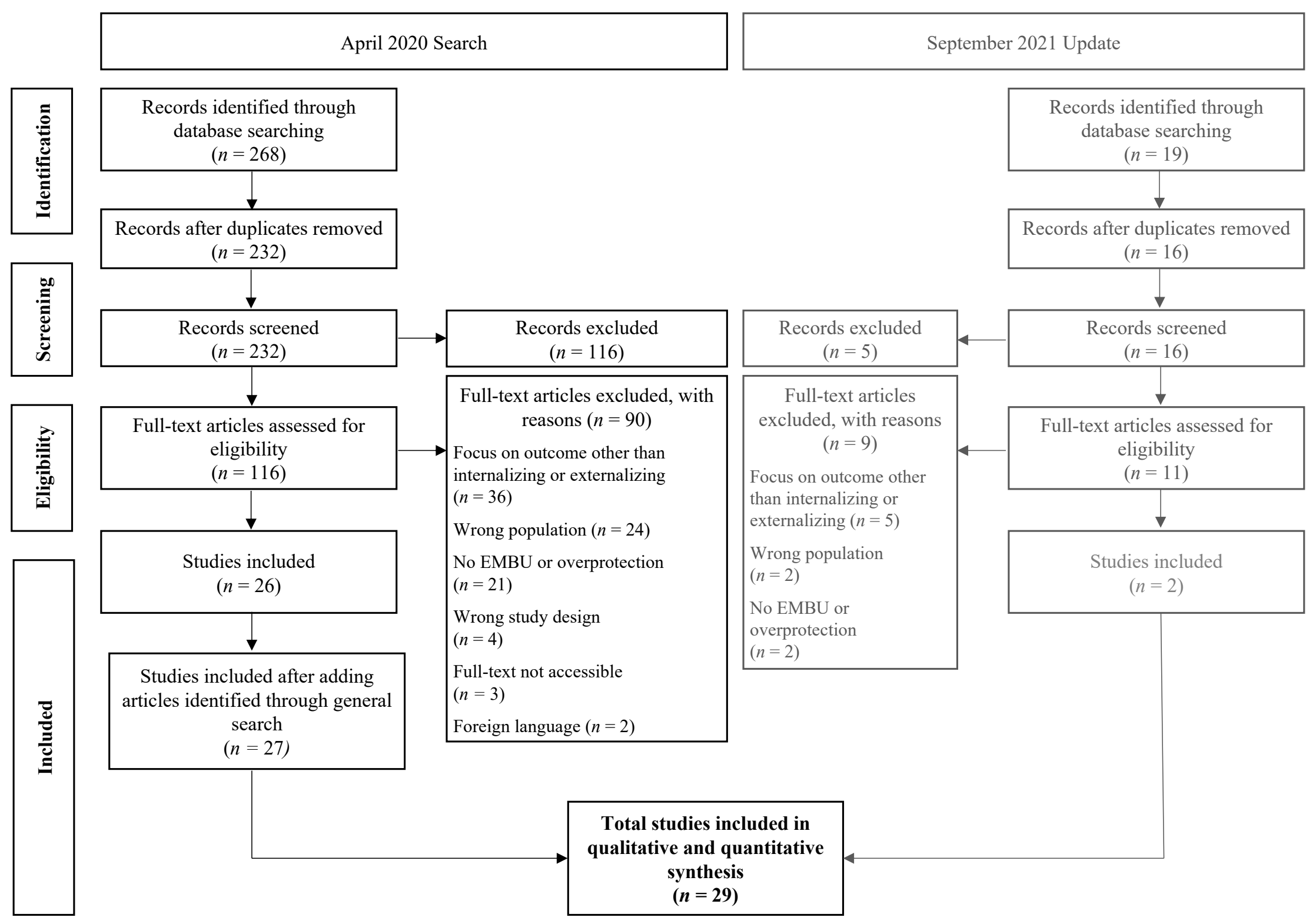


Figure 2

Forest Plot for Unadjusted Effect of Parental Overprotection as Assessed by the EMBU on Internalizing Problems.

[See next page (p. 38) for Figure]

Note. Multiple effect sizes for a specific outcome may be included from the same study because effects were reported separately for different reporters of the exposure or outcomes (e.g., self-report and parent-report) or for different time points. $R E=$ random effects.

${ }^{a}$ Influential outlier. 
Affrunti \& Ginsburg, 2012, Anxiety

Affrunti \& Ginsburg, 2012, Generalized anxiety

Berkien et al., 2012, Internalizing problems

Berkien et al., 2012, Internalizing problems

Irons et al., 2006, Depression

Knappe et al., 2009, Social phobia

Liu et al., 2020, Non-suicidal self-injury

Liu et al., 2020, Non-suicidal self-injury

Liu et al., 2020, Repeated non-suicidal self-injury

Liu et al., 2020, Repeated non-suicidal self-injury

Liu et al., 2020, Severe non-suicidal self-injury

Liu et al., 2020, Severe non-suicidal self-inj

Mousavi et al., 2016, Separation anxiety

Mousavi et al., 2016, OCD symptoms

Mousavi et al., 2016, Panic/agoraphobia

Mousavi et al., 2016, Injury fears

Mousavi et al., 2016, Generalized anxiety

Mousavi et al., 2016, Anxiety

Mousavi et al., 2016, Anxiety

Mousavi et al., 2016, Anxiety

Mousavi et al., 2016, Anxiety

Mousavi et al., 2016, Anxiety

Muris et al., 2011, Other anxiety disorder

Muris et al., 2011, Social anxiety

Muris et al., 2011, Other anxiety disorders

Muris et al., 2011, Social anxiety

Muris et al., 2011, Other anxiety disorders

Muris et al., 2011, Depression

Niditch \& Varela, 2012, Anxiety

Nishikawa et al., 2010, Internalizing problems (girls) ${ }^{a}$

Nishikawa et al., 2010, Internalizing problems (girls)

Nishikawa et al., 2010, Internalizing problems (girls)

Oldehinkel et al., 2006, Depression (girls)
Oldehinkel et al., 2006, Depression (boys)

Sentse et al., 2009, Internalizing problems (girls)

Sentse et al., 2009, Internalizing problems (boys)

Smári et al., 2010, OCD symptoms

Stevens et al., 2015, Anxiety

van Brakel et al., 2006, Anxiety

Xia \& Qian, 2001, OCD symptoms

Xia \& Qian, 2001', Depression

Xia \& Qian, 2001, Anxiety

Xia \& Qian, 2001', Phobic anxiety

Xia \& Qian, 2001, Somatization

Xia \& Qian, 2001, OCD symptoms

Xia \& Qian, 2001, Depression

Xia \& Qian, 2001, Anxiety

Xia \& Qian, 2001, Phobic anxiety

Xu et al., 2017, Social anxiety

Xu et al., 2017, Social anxiety

Young et al., 2013, Anxiety

Multilevel RE Model for All Internalizing Outcomes $(Q=237.19, \mathrm{df}=57, p=0.00)$

Model without Influential Outliers ${ }^{\mathrm{a}}(Q=220.04, \mathrm{df}=56, p=0.00)$
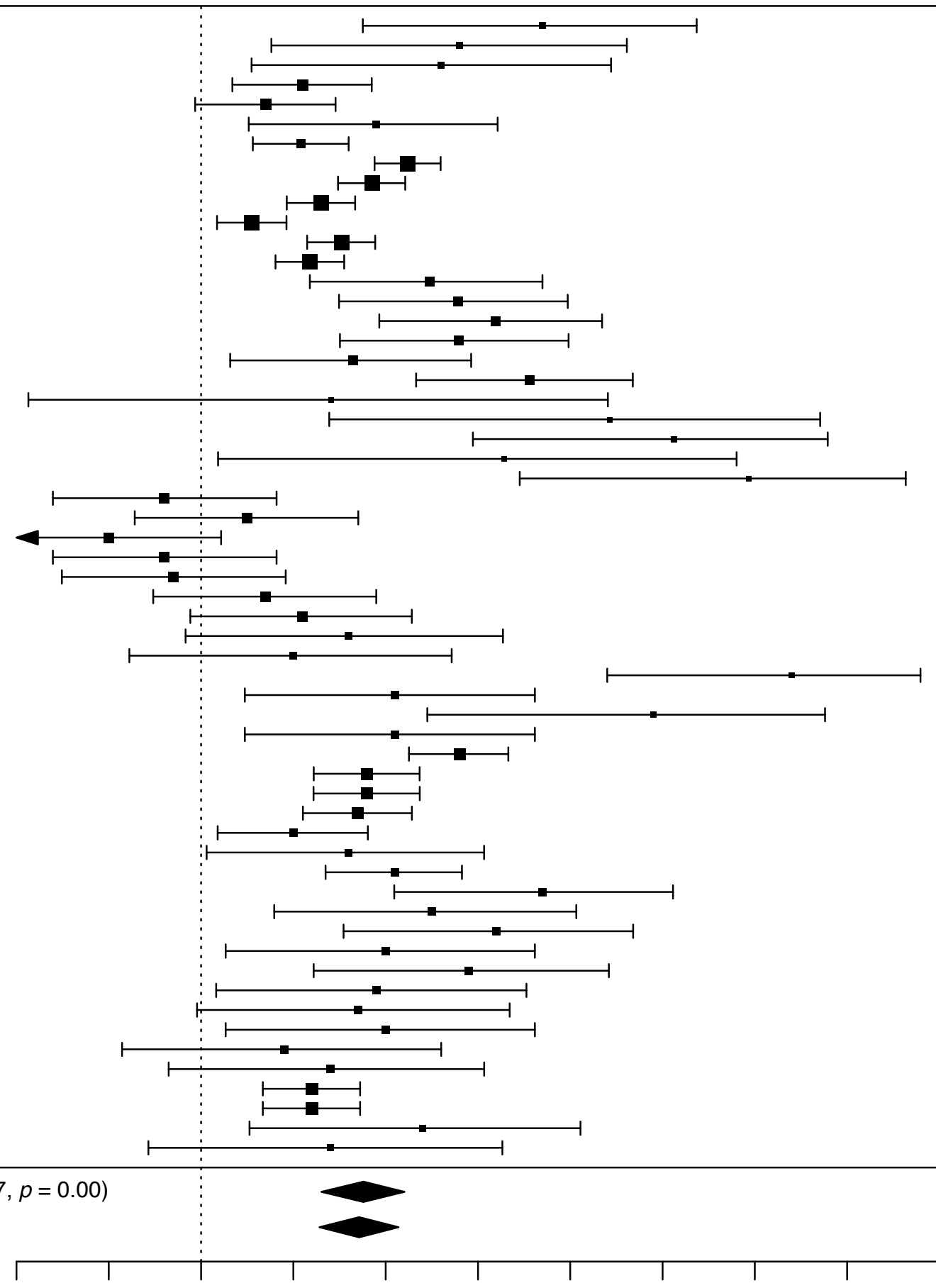

$-0.2-0.1$

0.1

0.2

0.4

0.5

0.6

0.7

0.8

Correlation Coefficient
$0.37[0.18,0.54$

$0.26 \quad 0.05,0.44$

$0.11[0.03,0.18$

$0.07[-0.01,0.15$

0.19 [0.05, 0.32

$0.220 .19,0.26$

$0.190 .15,0.22$

0.05 0.02, 0.09

0.15 0.11, 0.19

0.12 0.08, 0.15

$280.15,0.40$

0.32

$0.160 .03,0.29$

$0.36-0.23,0.47$

$0.14[-0.19,0.44$

$0.44[0.14,0.67$

$0.59+0.35,0.76$

$-0.04-0.16,0.08$

$0.05-0.07,0.17$

$-0.10-0.22,0.02$

$-0.04-0.16,0.08$

$-0.03-0.15,0.09$

$0.11-0.01,0.23$

$0.10 .02,0.33$

0.64 [ $0.44,0.78$

$0.210 .05,0.36$

0.210 .0 .36

$0.28 \quad 0.23,0.33$

$0.180 .12,0.24$

$0.17 \quad 0.11,0.23$

$0.10 \quad 0.02,0.18$

0.16 .

37 0.21, 0.51

0.25 0.08, 0.41

$0.20 \quad 0.03,0.36$

$0.290 .12,0.44$

0.19 0.02, 0.35

0.17 [-0.00, 0.33

$0.20[0.03,0.36$

0.09 [-0.09, 0.26

$0.14[-0.04,0.31$

0.12 0.07, 0.17 $0.1240 .07,0.17$ $0.14[-0.06,0.33$ 
Figure 3

Forest Plot for Unadjusted Effect of Parental Overprotection as Assessed by the EMBU on Externalizing Problems.

[See next page (p. 40) for Figure]

Note. Multiple effect sizes for a specific outcome may be included from the same study because effects were reported separately for different reporters of the exposure or outcomes (e.g., self-report and parent-report) or for different time points. $R E=$ random effects.

${ }^{\text {a }}$ Influential outlier. 
Berkien et al., 2012, Externalizing problems Berkien et al., 2012, Externalizing problems Brinksma et al., 2021, ADHD symptoms Brinksma et al., 2021, ADHD symptoms Buschgens et al., 2010, Inattention Buschgens et al., 2010, Inattention Buschgens et al., 2010, Hyperactivity/impulsivity Buschgens et al., 2010, Aggression Buschgens et al., 2010, Aggression Buschgens et al., 2010, Delinquency Buschgens et al., 2010, Delinquency Muris et al., 2011, Externalizing problems Nishikawa et al., 2010, Externalizing problems (girls) Nishikawa et al., 2010, Externalizing problems (boys) Nishikawa et al., 2010, Externalizing problems (girls) Nishikawa et al., 2010, Externalizing problems (boys) Sentse et al., 2009, Externalizing problems (girls) Sentse et al., 2009, Externalizing problems (boys) Veenstra et al., 2006, Antisocial behavior (girls) ${ }^{a}$ Veenstra et al., 2006, Antisocial behavior (boys) Villegas-Pantoja et al., 2018, Hazardous alcohol use (boys) Villegas-Pantoja et al., 2018, Dependence symptoms (boys) Villegas-Pantoja et al., 2018, Harmful alcohol use (boys) Villegas-Pantoja et al., 2018, Hazardous alcohol use (girls) Villegas-Pantoja et al., 2018, Dependence symptoms (girls) Villegas-Pantoja et al., 2018, Harmful alcohol use (girls) Xia \& Qian, 2001, Hostility Xia \& Qian, 2001, Hostility Brinksma et al., 2021, ADHD symptoms

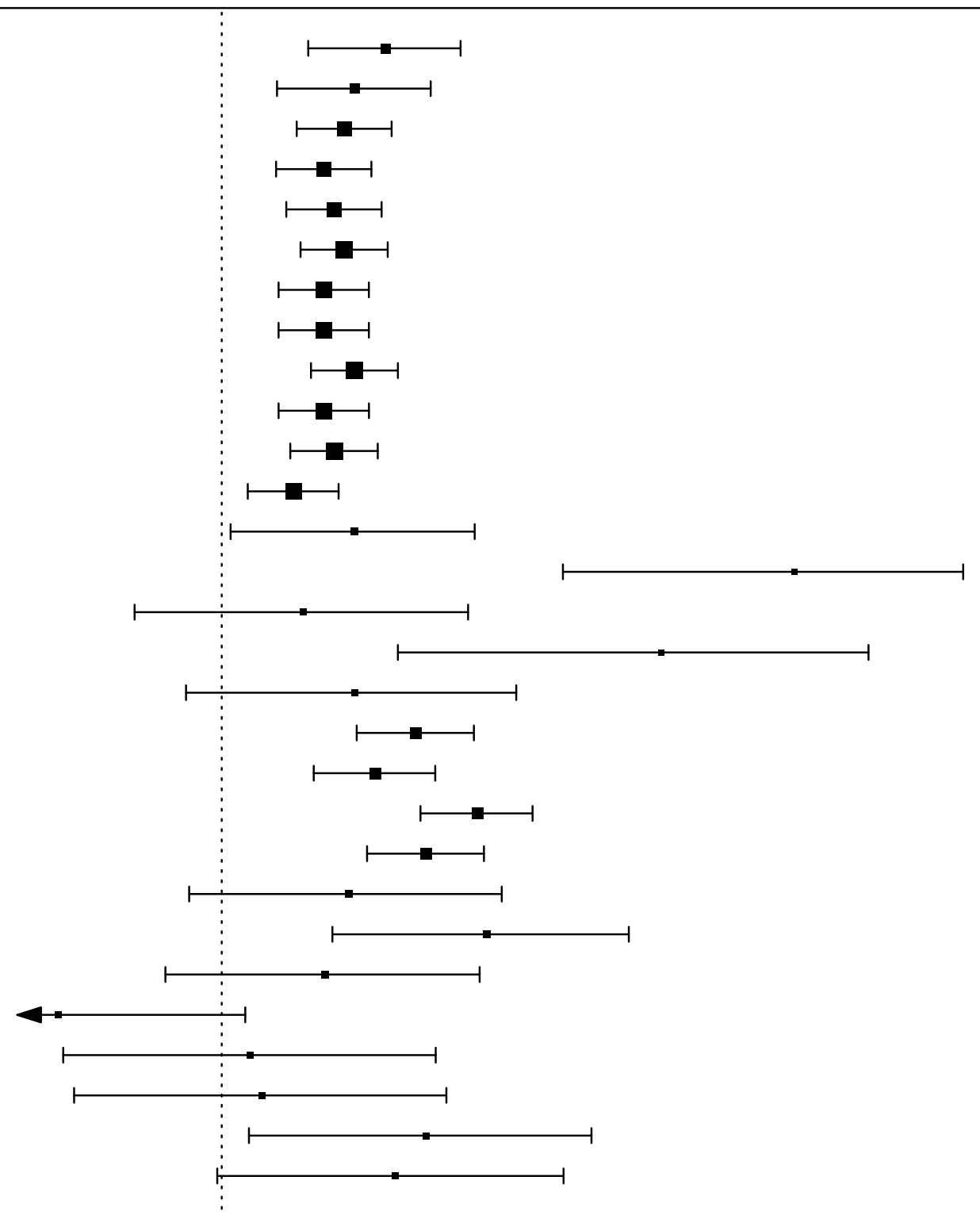

Multilevel RE Model for All Externalizing Outcomes $(Q=76.40, \mathrm{df}=28, p=0.00)$

Model without Influential Outliers ${ }^{\mathrm{a}}(Q=56.78, \mathrm{df}=27, p=0.00)$
$0.16[0.08,0.23]$

$0.13[0.05,0.20]$

$0.12[0.07,0.17]$

$0.10[0.05,0.15]$

$0.11[0.06,0.16]$

$0.12[0.08,0.16]$

0.10 [ $0.06,0.14]$

$0.10[0.06,0.14]$

$0.13[0.09,0.17]$

$0.10[0.06,0.14]$

$0.11[0.07,0.15]$

0.07 [ $0.03,0.11]$

$0.13[0.01,0.25]$

0.56 [ $0.33,0.73]$

$0.08[-0.09,0.24]$

$0.43[0.17,0.63]$

$0.13[-0.03,0.29]$

$0.19[0.13,0.25]$

0.15 [ $0.09,0.21]$

$0.25[0.19,0.30]$

$0.20[0.14,0.26]$ $0.12[-0.03,0.27]$

$0.26[0.11,0.40]$

$0.10[-0.06,0.25]$

$-0.16[-0.33,0.02]$

$0.03[-0.16,0.21]$

$0.04[-0.14,0.22]$

$0.20[0.03,0.36]$

$0.17[-0.00,0.33]$

$0.15[0.11,0.18]$

$0.14[0.11,0.17]$

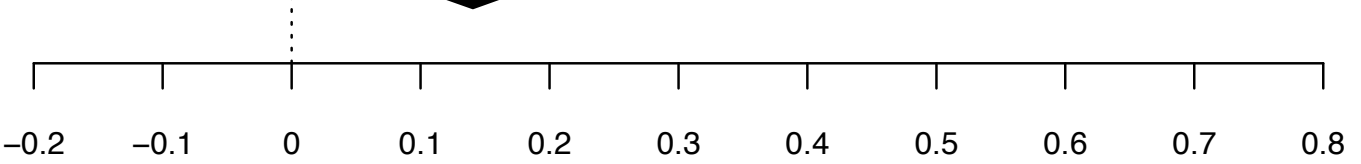

Correlation Coefficient 


\section{Figure 4}

Forest Plot for Adjusted Effect of Parental Overprotection as Assessed by the EMBU on Internalizing Problems.

[See next page (p. 42) for Figure]

Note. Multiple effect sizes for a specific outcome may be included from the same study because effects were reported separately for different reporters of the exposure or outcomes (e.g., self-report and parent-report) or for different time points. No influential outliers were identified. $R E=$ random effects. 


\section{Study, Publication Year, and Outcome}

Affrunti \& Ginsburg, 2012, Total anxiety

Affunti \& Ginsburg, 2012, Generalized anxiety

Aerkien a

Berkien et a., 2012, Internalizing problems

Haciomeroglu \& Karanci, 2014 OCD symptoms

Haciomeroglu \& Karanci, 2014, OCD symptoms

Irons et al., 2006, Depression

Janssens et al., 2009, Functional somatic problem

Janssens et al., 2009, Functional somatic problems (girls

Janssens et al., 2009, Functional somatic problems (girls

Janssens et al., 2009, Functional somatic problems (boys)

Knappe et al., 2009, Social phobia

Liu et al., 2020, Non-suicidal self-injury

(a., 2020, Non-suicidal self-injury

iu et al., 2020, Repeated non-suicidal self-injury

Liu et al, 2020, Severe non-suicidal self-iniury

Liu et al., 2020, Severe non-suicidal self-injury

Mousavi et al., 2016, Anxiety

Mousavi et al, 2016, Anxiety

Mousavi et al., 2016, Anxiety

Mousavi et al., 2016, Anxiety

Mousavi et al. 2016, Anxiety

Muris et al. (a), 2003, Internalizing problems

Muris et al. (a), 2003, Internalizing problem

Muris et al. a), 2003 , Anxious/depressed

Muris et al. (a), 2003, Anxious/depressed

Muris et al. (a), 2003, Anxious/depressed

Muris et al. a), 2003 , Somatic complain

Muris et al. (b), 2003, Anxiety (boys)

Muris et al. (b), 2003, Anxiety (girls)

Muris et al. (b), 2003, Anxiety (boys)

Muris et al., 2011, Social anxiety

Muris et al., 2011, Other anxiety disorders

Muris et al., 2011, Other anxiety disorders

Niditch \& Varela, 2012, Anxiety

Oldehinkel at

Roelofs et al 2006 , Anxiety

Roelofs et al., 2006, Anxiety (girls)

Roelofs et al., 2006, Depression (boys)

Roelofs et al., 2006, Depression (girls)

Roelofs et al., 2006, Anxiety (boys)

Roelors et al., 2006, Anxiety (girls boys)

Roelofs et al., 2006, Depression (girls)

Sentse et al., 2009, Internalizing problems

Smári et al., 2010, OCD symptoms

Stevens et al., 2015, Anxiety symptoms

van Oort et al 2011 , Anxiety

Xu et al 2017 Social anxiety

Young et al., 2013, Anxiety

Multilevel RE model for All Internalizing Outcomes $(Q=573.50, \mathrm{df}=57, p=0.00$

Model based on Complete Case Analysis $(Q=552.79, \mathrm{df}=53, p=0.00$ )
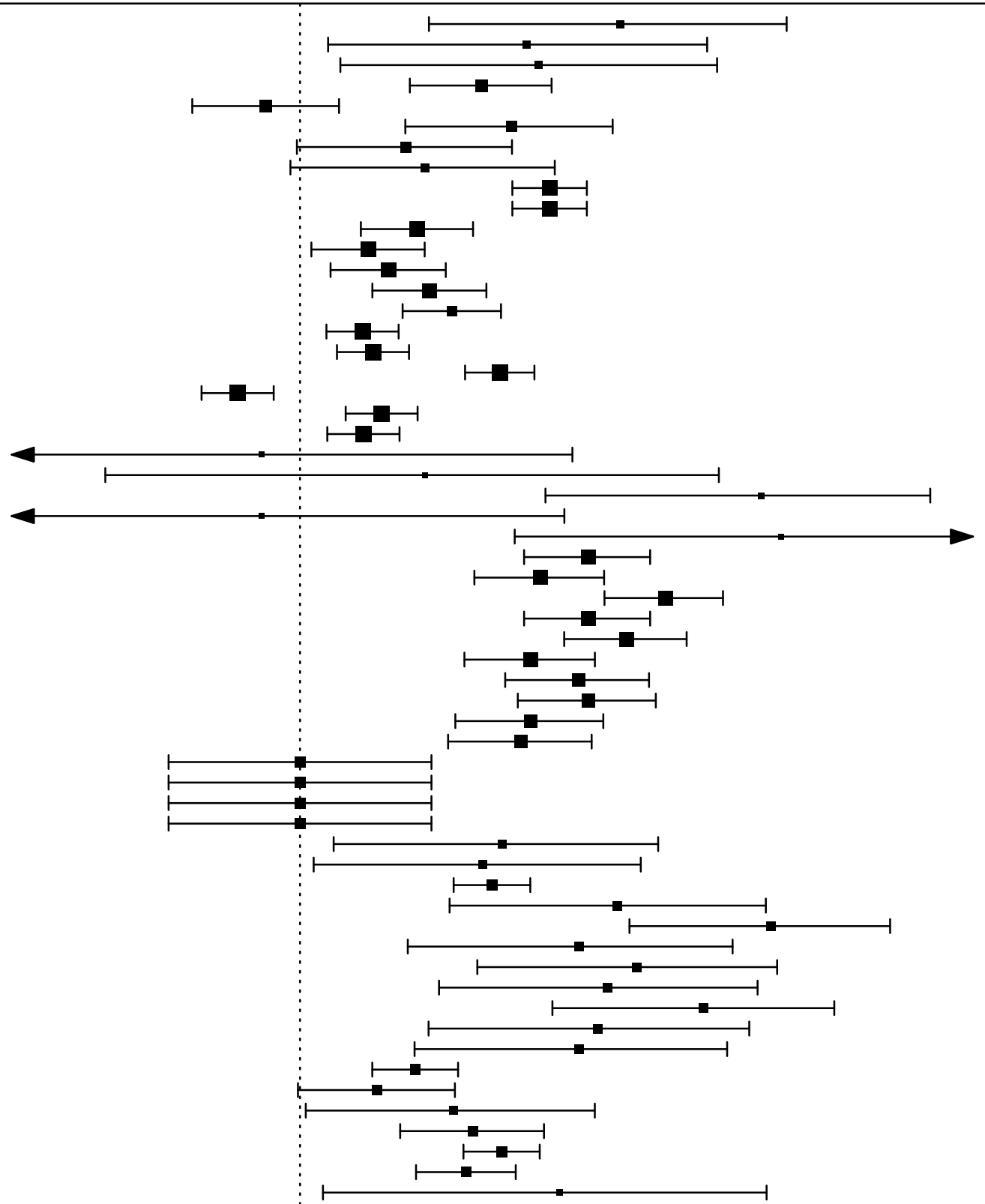

Partial Correlations [95\% Cl]

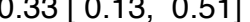

\begin{tabular}{lll}
0.25 & 0.04, & 0.43 \\
0.19 & 0.11, & 0.26 \\
\hline
\end{tabular}

$-0.04[-0.11,0.04$

$0.11[-0.00,0.22$

. 13 [-0.01, 0.26

$0.26[0.22,0.30$

$0.120 .06,0.18$

0.09-10.0.

$0.13-0.08,0.19$

\begin{tabular}{l|ll}
0.16 & 0.11, & 0.21 \\
0.07 & 0.03, & 0.10
\end{tabular}

$0.08 \quad 0.04,0.11$

$0.21[0.17,0.24$

$0.070 .03,0.10$

$-0.04[-0.36,0.28$

$0.13[-0.20,0.44$

$0.48[0.26,0.66$

$0.04[-0.35,0.27$

$0.300 .23,0.36$

0.25 0.18, 0.32

$0.300 .23,0.36$

$0.340 .27,0.40$

$0.290 .21,0.36$

$0.30-0.23,0.37$

0.24 0.16, 0.32

$.00[-0.14,0.14$

$0.00-0.14,0.14$

$0.00-0.14,0.14$

00 -0.14, 0.14

$0.190 .01,0.3$

$0.200 .16,0.24$

0.33 0.16, 0.48

$0.290 .11,0.45$

$0.350 .18,0.50$

0.32 0.14, 0.48

0.42 .

$0.290 .12,0.44$

0.12 0.08, 0.16

$0.16[0.01,0.31$

$0.18-10,0.25$

$0.170 .12,0.22$

$0.27[0.02,0.49$ ]

0.18 [0.14, 0.23]

$0.19[0.15,0.24]$

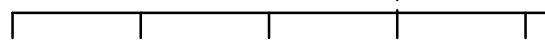

0.1

0.2

0.3

0.4

0.5

0.6

Partial Correlation Coefficient 


\section{Figure 5}

Forest Plot for Adjusted Effect of Parental Overprotection as Assessed by the EMBU on Externalizing Problems.

[See next page (p. 44) for Figure]

Note. Multiple effect sizes for a specific outcome may be included from the same study because effects were reported separately for different reporters of the exposure or outcomes (e.g., self-report and parent-report) or for different time points. $R E=$ random effects.

${ }^{\mathrm{a}}$ Influential outlier. 
Berkien et al., 2012, Externalizing problems Berkien et al., 2012, Externalizing problems Buschgens et al., 2010, Inattention Buschgens et al., 2010, Inattention Buschgens et al., 2010, Hyperactivity/impulsivity Buschgens et al., 2010, Aggression Buschgens et al., 2010, Aggression Buschgens et al., 2010, Delinquency Buschgens et al., 2010, Delinquency Mukhtar \& Mahmood, 2018, Relational aggression Mukhtar \& Mahmood, 2018, Relational aggression Muris et al. (a), 2003, Externalizing problems Muris et al. (a), 2003, Externalizing problems Muris et al. (a), 2003, Aggression

Muris et al. (a), 2003, Delinquency

Muris et al. (a), 2003, Aggression

Muris et al. (a), 2003, Delinquency

Roelofs et al., 2006, Aggression (boys) Roelofs et al., 2006, Aggression (girls) Roelofs et al., 2006, Aggression (boys) Roelofs et al., 2006, Aggression (girls)

Ruchkin et al., 1998, Hostility

Ruchkin et al., 1998, Anger

Ruchkin et al., 1998, Verbal aggression

Ruchkin et al., 1998, Physical aggression

Ruchkin et al., 1998, Hostility

Ruchkin et al., 1998, Anger

Ruchkin et al., 1998, Verbal aggression

Ruchkin et al., 1998, Physical aggression

Sentse et al., 2009, Externalizing problems

Veenstra et al., 2006, Antisocial behavior

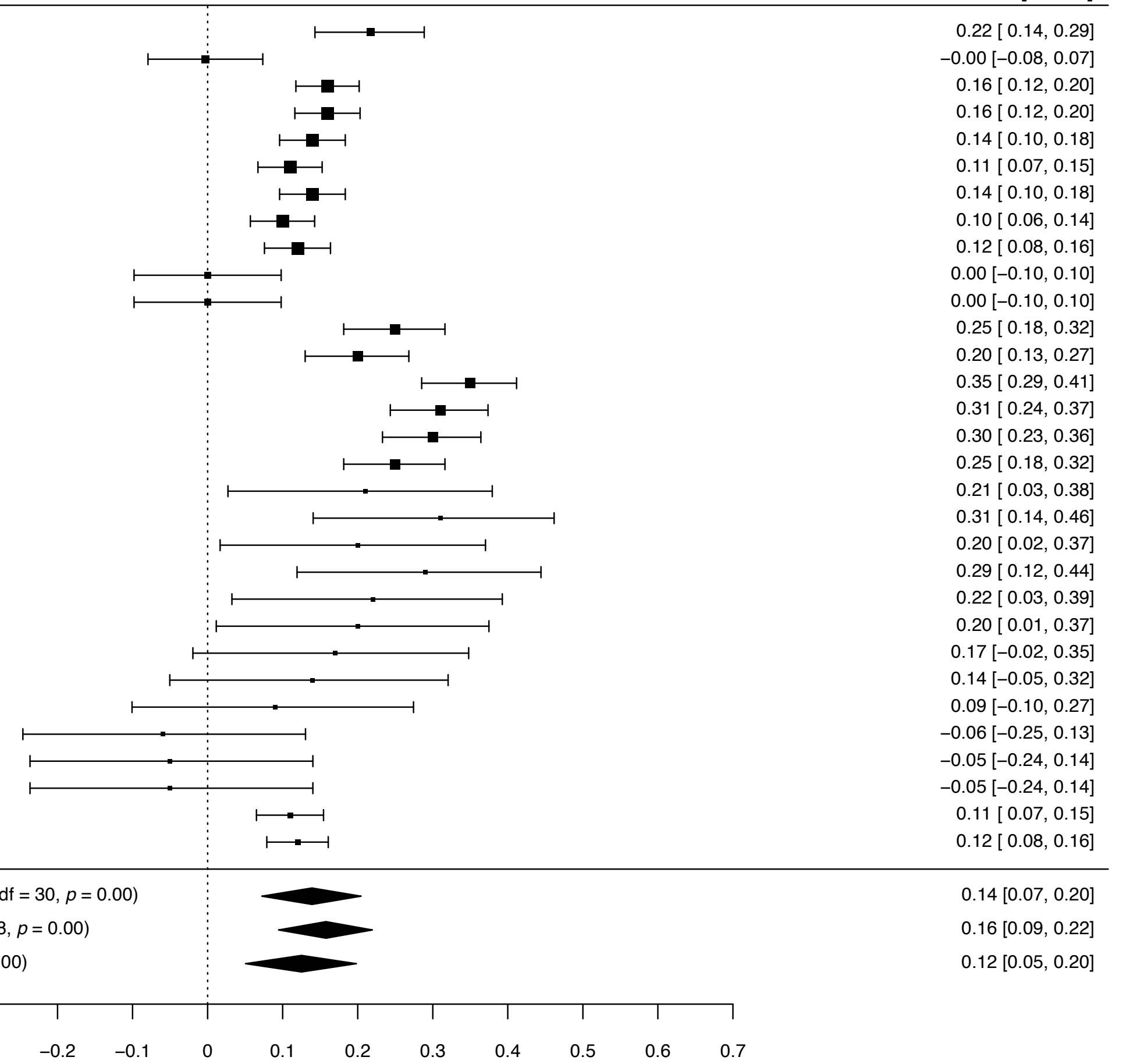

$\begin{array}{lllllllllll}-0.3 & -0.2 & -0.1 & 0 & 0.1 & 0.2 & 0.3 & 0.4 & 0.5 & 0.6 & 0.7\end{array}$

Multilevel RE Model for All Externalizing Outcomes $(Q=166.27, \mathrm{df}=30, p=0.00)$

Model based on Complete Case Analysis $(Q=147.35, \mathrm{df}=28, p=0.00)$

Model without Influential Outliers ${ }^{\mathrm{a}}(Q=163.12, \mathrm{df}=29, p=0.00)$

Partial Correlation Coefficient 